\title{
CAMBIO CLIMÁTICO Y POLÍTICA TURÍSTICA EN ESPAÑA: DIAGNÓSTICO DEL LITORAL MEDITERRÁNEO ESPAÑOL
}

\author{
Jorge Olcina Cantos \\ J. Fernando Vera-Rebollo \\ Universidad de Alicante
}

\section{RESUMEN}

El litoral mediterráneo español es una de las áreas de Europa donde pueden ser más evidentes los cambios en las condiciones climáticas durante las próximas décadas. La subida de temperaturas y el descenso de precipitaciones son factores que obligan a tomar medidas de adaptación que reduzcan el disconfort térmico previsto y la escasez de recursos de agua convencional derivada de una disminución de las lluvias. La actividad turística es un sector vulnerable ante el cambio climático y sus riesgos asociados y ha de ir adaptándose a la nueva realidad climática prevista. Junto a los protocolos internacionales de reducción de emisiones de gases de efecto invernadero, se han puesto en marcha planes de adaptación al cambio climático, con medidas concretas para cada sector económico. Se analizan las políticas de adaptación al cambio climático desarrolladas en España en los últimos años, con especial detalle en las regiones del litoral mediterráneo, por la gran importancia económica y territorial de la actividad turística en ellas y los preocupantes efectos que se señalan en los modelos de cambio climático para las próximas décadas en estos territorios.

Palabras clave: cambio climático; política turística; litoral mediterráneo español.

Recibido: 7 de diciembre de 2015

Devuelto para su revisión: 5 de abril de 2016

Aceptado: 5 de junio de 2016

Laboratorio de Climatología e Instituto Universitario de Investigaciones Turísticas. Universidad de Alicante. Apartado 99.03080 ALICANTE (España).E-mail: jf.vera@ua.es, jorge.olcina@ua.es 


\title{
Climate change and tourism policy in Spain: \\ Diagnosis in the Spanish Mediterranean coast
}

\begin{abstract}
Spanish Mediterranean coast is one of the European areas where may be more obvious changes caused by climatic conditions in the coming decades. Rising temperatures and decreased rainfall forced to take measures for adaptation to reduce the projected thermal discomfort and the reduction of conventional water resources that would result in a decreased rainfall. Tourism is a very vulnerable sector to climate change and its associated risks that must be adapted to the expected new climate conditions. Together with international protocols to reduce emissions of greenhouse gases, several countries have set up plans for adaptation to climate change, with specific measures for each economic sector. In this paper, we analyze climate change adaptation policies developed in Spain in recent years, with special detal in regions of the Mediterranean coast, due to grear economic and territorial importante of tourism in them, and worrying effects listed in the climate change models for coming decades in these territories.
\end{abstract}

Keywords: climate change; tourism policy; Spanish Mediterranean coast.

\section{TURISMO Y CAMBIO CLIMÁTICO EN EL LITORAL MEDITERRÁNEO ESPAÑOL: ESTADO DE LA CUESTIÓN}

El turismo es un sector estratégico en la Unión Europea, como queda de manifiesto en el Tratado de Lisboa (2009) y en la «Declaración de Madrid» (2010), bajo la premisa de posicionar a esta actividad como uno de los sectores prioritarios de su economía, con estrategias específicas de crecimiento y consolidación. Así queda reflejado, por ejemplo, en el marco presupuestario de la UE (2014-2020) y en la inclusión del turismo como objetivo específico en el Programa COSME para la PyME europea.

La Comisión Europea viene desarrollando, desde 2011, una serie de acciones tendentes a estimular la competitividad del sector turístico europeo y que abarcan aspectos diferentes, desde el apoyo al turismo cultural e itinerarios culturales europeos, la innovación en la industria turística, la mejora de la capacitación profesional y la formación, la extensión de la temporada turística, la base del conocimiento socioeconómico en turismo y la información sobre tendencias de mercado, la promoción del desarrollo sostenible y las iniciativas sobre turismo accesible, hasta el avance hacia una «verdadera marca Europa» para destinos turísticos. Para ello, se indica explícitamente la necesidad de maximizar el potencial de las políticas e instrumentos financieros de la UE que favorezcan el desarrollo del turismo. Y entre este cúmulo de acciones indicadas, se señala el análisis de la política de turismo y de la cuestiones que afectarán a la forma de hacer turismo y el modo en que los cambios demográfico y climático afectarán al turismo. No obstante, no existe ningún instrumento específico orientado a la acción con esta finalidad.

En el caso de España la importancia del turismo como sector económico es innegable. De acuerdo con el informe de la Organización Mundial del Turismo (OMT, 2014), ocupa 
la $3^{\text {a }}$ posición en el ranking mundial de llegadas de turistas internacionales, con más de 60 millones de llegadas de turistas internacionales, lo que la sitúa solo por detrás de Francia, primer destino mundial, y de Estados Unidos. En su conjunto, las cifras de llegadas por turismo internacional en España representan alrededor del 10\% del turismo mundial. Además, si se toma como referencia el total de ingresos en divisas, España ocupa la segunda posición, después de Estados Unidos, con más de 62 mil millones de dólares. En definitiva, la actividad turística es de una enorme importancia para la economía nacional, con un movimiento económico total cifrado en el 10\% del PIB español (Roselló, 2011).

Según el estudio Travel and Tourism Competitiveness Report, publicado por el World Economic Forum (2015), España es el primer país del top 10 del Travel and Tourism Index 2015 , resultado de una mejora de su posición desde 2011, ascendiendo cuatro posiciones en apenas dos años. Esta situación es el resultado de que, tanto la administración central como la mayor parte de gobiernos autonómicos, entienden el turismo como una prioridad en sus políticas, tal y como se observa en los esfuerzos realizados en promoción y fomento de esta actividad, a pesar de las dificultades económicas.

Es por ello que preocupan los posibles efectos que el proceso de calentamiento térmico planetario pueda tener en esta actividad económica y en los espacios geográficos donde se desarrolla puesto que, si no se diseñan programas de mitigación y adaptación eficaces, las consecuencias en términos de generación de riqueza y puestos de trabajo serán notables (Gómez Martín; Armesto; Martínez Ibarra, 2014). El turismo es, junto a la agricultura, la actividad económica con más alto grado de exposición a los efectos del calentamiento climático. En términos de análisis de riesgo la agricultura es una actividad más expuesta pero menos vulnerable, mientras que el turismo es una actividad más vulnerable con una exposición variable según la modalidad que se practique en el espacio geográfico: muy elevada, por ejemplo, en el caso del turismo de sol y playa, del turismo de nieve o en el turismo urbano de grandes ciudades. El análisis de los factores espaciales que permiten el desarrollo de la actividad turística en un territorio ha cobrado creciente protagonismo en la investigación científica del turismo. En el contexto actual de globalización, de cambios económicos acelerados, cualquier alteración en los elementos del medio físico pueden afectar a la actividad económica de un territorio. El mantenimiento de los recursos territoriales que favorecen la actividad turística en los principales destinos mundiales se presenta, en la actualidad, como proceso lleno de incertidumbres debido a las modificaciones que, de forma manifiesta, experimentan las condiciones climáticas terrestres (Amelung; Nicholls; Viner, 2007).

Los efectos posibles del cambio climático son conocidos, desde hace años, por el sector turístico. A la celebración regular, desde 2003, de conferencias internacionales sobre la cuestión, bajo los auspicios de la Organización Mundial del Turismo (Djerba, Davos, Copenhague, Cancún, Durban, Doha, Kenia) y de congresos mundiales sobre aspectos concretos de la relación entre cambio climático y turismo, asimismo organizados por la OMT, (turismo de montaña y nieve; turismo y transporte aéreo), se une la lucha contra el cambio climático en los planes elaborados por los gobiernos en los países desarrollados y las medidas puestas en marcha, desde el ámbito privado del propio sector turístico. Hay, por tanto, un nivel de conocimiento elevado de esta cuestión en consonancia con la importancia de los efectos que puede suponer el cambio climático en esta actividad econó- 
mica y en los territorios donde se desarrolla. Otra cuestión es el grado real de preparación existente y la efectividad de las medidas desarrolladas. Sirva como muestra la aplicación de la tasa de emisiones de CO2 para las compañías aéreas puesta en marcha en la Unión Europea y que ha desatado serias reacciones en contra por parte de compañías de países exteriores (EE.UU., China, India), lo que está impidiendo su cumplimiento.

En el informe sobre adaptación de la economía al cambio climático (KPMG, 2008) ${ }^{1}$ se manifiesta el escaso grado de preparación del turismo ante el cambio climático, frente al elevado nivel de percepción del riesgo que este proceso supone para el sector. En España, el informe sobre la respuesta de la sociedad ante el cambio climático (Meira Cartea, dir. , 2013) $)^{2}$ señala que apenas el $43 \%$ de la muestra encuestada considera probable que se experimente una disminución de la actividad turística en nuestro país a medio plazo (horizonte 2030) por efecto del cambio climático, frente a un 51\% que lo estima poco o nada probable. Es un resultado que manifiesta una preocupación baja de la sociedad española ante el problema del cambio climático. Por contra, el aspecto que más valoración de probabilidad real de desarrollo presenta en la muestra analizada $(86,3 \%)$ es el relativo a la génesis más frecuente de períodos de sequía. Es significativo comprobar, asimismo, que dentro de la división en áreas climáticas que se ha realizado en este informe, la zona «mediterránea» (litoral) es la que estima menos probable (sólo un $48 \%$ lo considera probable) el desarrollo de disminución significativa de la actividad turística a medio plazo (2030), frente a otras zonas climáticas donde la actividad turística es menos destacada (montaña, 52\%; interior, 67\%) (KPMG, 2008).

En la investigación científica del cambio climático y sus efectos para la actividad turística se ha pasado, en la última década, de la descripción física del fenómeno y de los efectos estimados por la modelización climática en los territorios, al análisis del impacto de las proyecciones de clima futuro sobre la actividad económica (economía), al estudio y elaboración de propuestas de adaptación (administración), al análisis de los efectos sobre recursos esenciales para la actividad turística (geografía) y, asimismo, a la valoración de la percepción del cambio climático en espacios turísticos (sociología, geografía). Preocupa ahora fundamentalmente la parte social y económica del cambio climático en relación con la actividad turística, mientras siguen las investigaciones de la componente física del proceso (actualización de informes por parte del IPCC).

Desde la economía, a partir de la utilización de modelos de medición del impacto sobre flujos turísticos, se han señalado posibles cambios en la actividad turística a consecuencia del cambio climático ${ }^{3}$. Preocupa, especialmente, las alteraciones en la cuota de mercado que la subida de temperaturas puede causar en las modalidades de actividad turística de las regiones del mundo; y se manejan modelos de oferta y demanda que tienen en cuenta el cambio en las condiciones térmicas de los territorios objeto de análisis. Los trabajos

1 Vid. KPMG (2008) Climate changes your bussines. KPMG Global Sustainable Services, The Netherlands, 85 p. Disponible en: http://www.kpmg.com/EU/en/Documents/Climate_Changes_Your_Business.pdf

2 Vid. Meira Cartea, P.A. (dir.); Arto Blanco, M.; Heras Hernández, F.; Iglesias da Cunha, L.; Lorenzo Castiñeiras, J.J. y Montero Souto, P. (2013) La respuesta de la sociedad española ante el cambio climático, Fundación Mapfre, Madrid, 223 p.

3 El modelo más utilizado como referencia en estudios internacionales es el Hamburg Tourism Model. Puede consultarse en: http://www.fnu.zmaw.de/HTM.5681.0.html 
de investigación de los autores referentes en esta cuestión (Scott, Grossling, Hamilton, Dubois) abundan en esta línea, que se manifiesta, asimismo, en informes oficiales elaborados en los últimos años por parte de la ONU o la propia Organización Mundial del Turismo. Así, por ejemplo, Bigano, Hamilton y Tol (2008) han analizado los efectos del cambio climático en la actividad turística de la cuenca del Mediterráneo, a partir de la aplicación del modelo turístico de Hamburgo (HTM), y señalan una pérdida de llegada de turistas, para el horizonte 2100, en todos los países ribereños de la cuenca mediterránea que alcanzan porcentajes superiores al $40 \%$ en muchos del norte de África. Esta pérdida no llega a ser compensada por los desplazamientos internos de cada país (turismo doméstico) en estos países norteafricanos del Mediterráneo y ligeramente en los ribereños europeos. España, en este contexto, experimentará efectos ligeramente negativos, puesto que la pérdida de número de llegadas se compensa en gran medida por los movimientos del turismo doméstico. En relación con ello, Bujosa y Roselló (2011) han analizado las modificaciones en la estacionalidad turística de las provincias costeras españolas, a partir del aumento de $1^{\circ} \mathrm{C}$ en la temperatura media de todo el año y de los meses de temporada alta (verano). Según su análisis las provincias costeras más cálidas (este, sureste y sur peninsular) se verían negativamente afectadas por un aumento de las temperaturas, tanto para un aumento de temperaturas en temporada alta como en el conjunto del año; por el contrario, las provincias costera más frías del norte peninsular (litoral cantábrico, Galicia) e incluyendo Barcelona y Girona, se vería positivamente afectadas, por lo que su capacidad de atracción de turistas aumentaría.

Similares conclusiones contiene el estudio de Hein, Metzger y Moreno (2009) ${ }^{6}$ sobre los efectos del cambio climático en el turismo español, a partir del uso del «Índice de Clima Turístico» que integra diversas variables climáticas (vid. infra). En él se señala que la afluencia de turistas a nuestro territorio descenderá un 14\% en 2060 respecto a la registrada en 2004, siendo más importante en la estación estival -hasta un 26\%- debido a la pérdida de condiciones de confort climático en el área del mediterráneo, que es el litoral de mayor afluencia turística actual en verano. Como en el caso anterior, se indica la mejora en las condiciones climáticas estivales de la fachada cantábrica que puede compensar, a modo de estrategia de adaptación a desarrollar, la pérdida de mercado del litoral mediterráneo. En la investigación, no obstante, se indica la necesidad de mejorar estas proyecciones en un contexto económico global que tenga en cuenta los efectos del cambio climático en otros sectores económicos y que incorpore, asimismo, las fluctuaciones en los precios o el impacto de una posible desestacionalización de la temporada alta turística en el litoral mediterráneo.

4 Vid. Bigano, A. Hamilton, J.M. and Richard, S.J.Tol (2008) «Climate change and tourism in the Mediterranean», Working Paper FNU-157. Research Unit Sustainable and Global Change. Hamburg University. Disponible en http://www.fnu.zmaw.de/HTM.5681.0.html.

5 Vid. Bujosa, A. y Rosello, J. (2011) «Cambio climático y estacionalidad turística en España: un análisis del turismo doméstico de costa», Estudios de Economía Aplicada, vol. 29-3, pp. 863-880.

6 Vid. Hein, M., Metzger, J. and Moreno, A. (2009) «Potential impacts of climate change on tourism; a case study for Spain», Current Opinion in Environmental Sustainability n 1, , Elsevier, pp. 170-178. Disponible en: http://wordpress.reilumatkailu.fi/wp-content/uploads/2012/03/artikkeli3.pdf 
La investigación sobre los efectos del cambio climático en la actividad turística es clave para el diseño y puesta en marcha de medidas de mitigación y adaptación (SchmidtThomé \& Klein, 2013). En España, hasta el momento presente, se han abordado políticas de reducción del cambio climático de forma general, sin conocer realmente los efectos puede tener el calentamiento planetario en los espacios turísticos (Olcina Cantos, 2014 a). La mitigación de los efectos del cambio climático se ha centrado, básicamente, en las cuestiones energéticas (apuesta por energías alternativas, movilidad sostenible). Falta la integración del cambio climático y de sus peligros climáticos asociados en la ordenación territorial (escala regional y local), la determinación de las medidas estructurales que deban aplicarse en espacios turísticos de costa o de montaña, la aplicación de medidas fiscales (ecotasas) de finalidad ambiental, la planificación de los recursos de agua teniendo en cuenta las previsiones de los modelos climáticos; la planificación de los servicios sanitarios en áreas turísticas litorales en un escenario condicionado por el desarrollo más frecuente de extremos térmicos, especialmente en verano y el diseño de programas de educación y comunicación efectiva de las consecuencias del cambio climático y de los extremos atmosféricos vinculados (Olcina Cantos, 2014 b). Son algunas de las acciones que deben completar el diseño de planes y programas de acción ante el cambio climático y que deben estar fundamentadas en la integración de políticas a diversa escala y nivel (gobernanza del cambio climático).

La evaluación de medidas concretas de adaptación al cambio climático puestas en marcha en áreas turísticas, no ha merecido apenas estudios en los últimos años. En este caso, las escalas regional y local resultan claves al ser el escenario idóneo para el desarrollo de propuestas de adaptación específicas, con impacto socio-económico y territorial destacado. A escala internacional, se han evaluado programas de adaptación puestos en marcha en áreas urbanas (Barton, 2009; Hunt y Watkiss, 2011) aunque, en muchos casos, las medidas aplicadas no tienen una relación directa con la actividad turística o se integran dentro de proyectos generales de sostenibilidad en la escala local. Más atención ha merecido el estudio de efectos del cambio climático en elementos fundamentales para el desarrollo de las áreas turísticas, como el agua. Destacan, al respecto, las aportaciones generales sobre turismo, cambio climático y agua, llevadas a cabo por Gossling et al. (2012) y Amelung et al. (2007) o las dedicadas al ámbito mediterráneo, objeto del presente estudio, (Sauri et al., 2013), que analizan el impacto de la reducción de recursos de agua, prevista en la modelización climática, en la actividad turística de este espacio geográfico y las medidas adoptadas para mejorar su resiliencia.

El proyecto Espon-Climate $(2007-13)^{7}$ ha dibujado una serie de escenarios posibles de vulnerabilidad del territorio europeo ante el cambio climático; todo ello, teniendo en cuenta que cualquier evaluación de la vulnerabilidad se enfrenta a la incertidumbre de los modelos de cambio climático, del escenario de emisiones y de las tendencias futuras en el desarrollo socioeconómico (vid. figura 1).

7 Los resultados del proyecto Espon-Climate pueden consultarse en http://www.espon.eu/main/Menu_ Projects/Menu_AppliedResearch/climate.html 


\section{Figura 1 \\ VULNERABILIDAD POTENCIAL AL CAMBIO CLIMÁTICO Y CAPACIDAD DE ADAPTACIÓN EN LAS REGIONES EUROPEAS. PROYECTO ESPON-CLIMATE}

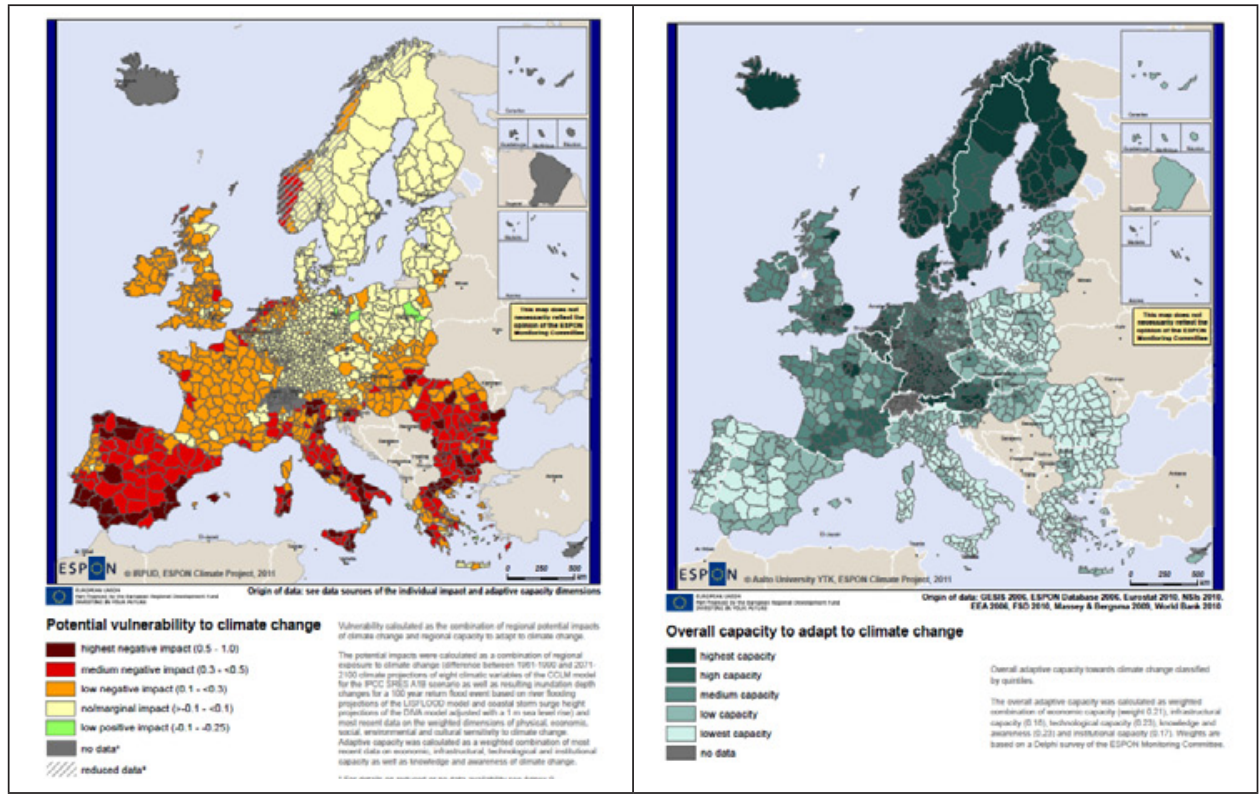

Fuente: Proyecto Espon-Climate (2013).

En el ámbito español, se ha seleccionado el litoral mediterráneo como área de análisis de los efectos del cambio climático en los recursos de agua y sus implicaciones en la actividad turística. Se han establecido categorías de vulnerabilidad en las áreas turísticas del Mediterráneo español en relación con el nivel de peligrosidad y con el grado de ocupación territorial y de preparación-adaptación ante la reducción de volúmenes de agua disponible prevista para finales del presente siglo. En esta clasificación (vid. figura 2), algunas áreas turísticas del sureste y sur del litoral mediterráneo muestran una elevada vulnerabilidad ante la reducción prevista de volúmenes de agua a causa del calentamiento planetario.

En su conjunto, España es un territorio especialmente expuesto a las posibles alteraciones climáticas debido a su posición geográfica en latitudes medias. Para el ámbito de la Europa meridional, el informe PESETA 2 de la JRC-Comisión Europea (2014) señala una pérdida del 1,5\% anual en el PIB nacional de estos países de la Europa meridional a partir de 2070 en el escenario -optimista- de subida térmica de $2^{\circ} \mathrm{C}$ a lo largo del presente siglo. Este porcentaje se eleva por encima del 2,5\% \% del PIB anual para subidas de temperatura por encima de $3^{\circ} \mathrm{C}$.

De forma que la realización de aproximaciones científicas al proceso del cambio climático y sus efectos en las actividades económicas es, desde el momento presente, una necesidad. Por tanto, es preciso conocer, con el mayor grado de aproximación posible, los 


\section{Figura 2}

\section{VULNERABILIDAD POTENCIAL A LA REDUCCIÓN DE RECURSOS DE AGUA PREVISTA EN LOS MODELOS DE CAMBIO CLIMÁTICO EN LAS ZONAS TURÍSTICAS DEL LITORAL MEDITERRÁNEO ESPAÑOL}

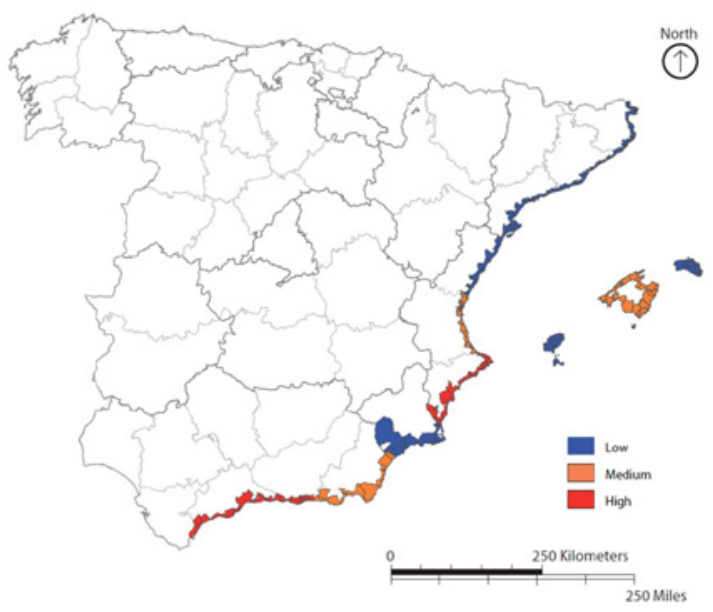

Fuente: Sauri et al. (2013).

efectos reales del calentamiento planetario en nuestras latitudes, comprender cómo puede afectar ello a los espacios turísticos y qué medidas pueden implementarse, a diversa escala, para mitigar sus consecuencias.

Hay tres procesos principales que pueden desarrollarse en nuestro país por efecto del cambio climático con implicaciones directas en la actividad turística: a) un aumento de los extremos atmosféricos (mayor peligrosidad climática); b) una reducción de precipitaciones y de volúmenes de agua disponible; y c) la pérdida de confort climático en el sur y este peninsular por aumento térmico en los meses centrales de verano.

Algunos estudios han señalado una serie de efectos, a medio y largo plazo, en la actividad turística española a consecuencia del proceso planetario de calentamiento térmico que, en esencia, se resumen $\mathrm{a}^{8}$ :

- Pérdida de cuota de mercado a nivel mundial, que pasará del 6\% al 4,8\% en 2030.

- Reducción a largo plazo en el número de llegadas de turistas, estimada en un $20 \%$ para el año 2080.

8 Vid. entre otros Bigano, A. Hamilton, J.M. and Richard, S.J.Tol (2008) «Climate change and tourism in the Mediterranean», Working Paper FNU-157. Research Unit Sustainable and Global Change. Hamburg University. Disponible en http://www.fnu.zmaw.de/HTM.5681.0.html.

- Rosello, J. (2011) «España, Turismo y cambio climático», Economistas nº 127, Madrid, en pp. 28-34.

- Bujosa, A. y Rosello, J. (2011) «Cambio climático y estacionalidad turística en España: un análisis del turismo doméstico de costa», Estudios de Economía Aplicada, vol. 29-3, pp. 863-880. 
- Pérdida relativa de importancia del turismo de sol y playa como producto turístico debido a la falta de confort climático en verano.

- Posibles cambios en los destinos turísticos interiores, con pérdida de importancia del litoral mediterráneo como mercado turístico y aumento de la cuota de mercado en el litoral cantábrico, que se percibirá ya en 2030.

La modelización climática en latitudes medias y, específicamente en el ámbito mediterráneo, señala una serie de alteraciones para las próximas décadas que ponen en duda el cumplimiento de las exigencias climáticas en los destinos turísticos (Besancenot, 1991):

- El aumento de días sin lluvia que, en principio, aumentaría las posibilidades de disfrute se verá contrarrestado por la reducción de volúmenes de agua disponible que puede poner en peligro los abastecimientos de espacios turísticos.

- Temperaturas más altas en verano y calor húmedo, poco soportable, en zonas litorales. Pérdida, por tanto, de confort climático.

- Incremento de extremos atmosféricos; por tanto, nivel de riesgo mayor.

La actitud ante el cambio climático por efecto invernadero y sus efectos en las actividades económicas debe ser la de la mejora constante de sus procesos físicos y la adaptación sensata frente a sus posibles consecuencias. Dada la enorme importancia económica del turismo en los territorios donde se desarrolla, la transmisión de lo que ocurre en cada momento, de los escenarios - cada vez más precisos- de cambio climático previstos y de las ventajas que supone la puesta en marcha, desde ahora, de medidas de mitigación y adaptación es la medida más eficaz frente a los «miedos» que este proceso puede generar en el propio sector turístico. Scott (2006) ha establecido una interesante relación entre el transcurso cronológico de la vida de un ser humano que hubiera nacido en el año 2000 y la manifestación progresiva de una modalidad de producto turístico que se hubiera iniciado ese mismo año (p.e. resort hotelero) y el funcionamiento de los diferentes efectos del cambio climático previstos en la modelización climática. La reducción de la nieve (estaciones de esquí) y de las precipitaciones (volúmenes de agua disponible) serán, para Scott, los primeros efectos visibles del cambio climático (hacia 2030) con implicaciones importantes en la actividad turística. Una persona que en 2000 tuviera 35 años de edad apenas notará las consecuencias del cambio global a lo largo de su vida; sin embargo, una persona nacida ese mismo año 2000 experimentará progresivamente los diferentes efectos climáticos y ambientales previstos hasta finales de presente siglo. Por ello, las medidas de mitigación o adaptación no pueden esperar a las decisiones políticas de ritmo casi siempre lento; deben activarse de forma inmediata en esta segunda década del siglo XXI puesto que, en caso contrario, la inacción en este asunto convierte el calentamiento térmico planetario climático en un proceso irreversible hacia 2060-709

9 Vid. Scott, D. (2008) Climate Change and Tourism: Responding to Global Challenges. Conferencia pronunciada en el marco del CTO / CRSTDP Regional Workshop The Bahamas, 18-19 March 2008. Disponible en http://www.onecaribbean.org/content/files/DavosReportOverviewDanScott.pdf 


\section{EFECTOS PREVISIBLES DEL CAMBIO CLIMÁTICO EN EL LITORAL MEDITERRÁNEO ESPAÑOL}

Desde que se publicó el primer Informe del IPCC (1988) hasta el momento actual, después de tres décadas de investigación de la hipótesis de cambio climático por efecto invernadero, hay una serie de manifestaciones en la atmósfera terrestre, cuya negación resulta cada vez más difícil:

- El incremento de temperaturas que se ha registrado en las tres últimas décadas no encuentra explicación, sólo, por causas exclusivamente naturales (radiación solar). Hay otro factor que está alterando el funcionamiento «normal» del balance energético del planeta, al originar una incentivación del poder calorífico de la radiación de onda larga, originada en la superficie terrestre y marina que no sale a la atmósfera exterior porque queda confinada en los primeros kilómetros de la atmósfera. Y este hecho está en relación con la presencia de gases primarios procedentes de la actividad económica humana $\left(\mathrm{CO}_{2}\right.$, oxido nitroso, metano) y depositados en la atmósfera o de la interacción de éstos con otros gases cuya contribución real al balance energético planetario sigue siendo una incertidumbre, como el ozono troposférico.

- Una atmósfera que pierde su equilibrio térmico y se vuelve más cálida o más fría es una atmósfera que registra procesos de reajuste energético más violentos; esto es, los tipos de tiempo cambian con más rapidez e intensidad. Se hace más frecuente la génesis de situaciones de rango extraordinario. Esto es especialmente notable en las latitudes medias al ser el escenario de desarrollo de los movimientos de expansión de las masas de aire frías (de norte a sur) y cálidas (de sur a norte).

- Desde 1980, las temperaturas han subido más en latitudes medias y altas que en las intertropicales, y especialmente, en el hemisferio norte. Ello se refleja tanto en los registros instrumentales de los observatorios como en las termografías realizadas a partir de datos de satélite (p.e. NASA earthobservatory).

El V Informe del IPCC (2013-14) señala que el cambio climático que pueda desarrollarse en las próximas décadas, si se sigue confirmando la hipótesis de efecto invernadero como parece, no supondrá sólo el aumento de las medias en el valor de la variable temperatura, sino que significará también en la variabilidad, de manera que el clima tiende a un calentamiento pero también a una mayor frecuencia en el registro de temperaturas extremas, con aumento de las medias máxima y mínimas. Al respecto, en el litoral mediterráneo español Quereda et al. (2001) han comprobado como el aumento de temperaturas medias anuales experimentado desde 1950 en localidades de la fachada este española se debe más al incremento de las mínimas nocturnas que de las máximas extremas diurnas que se hayan podido registrar ${ }^{10}$. Y esto, es también, un indicio de cambio climático, puesto que el ritmo térmico considerado normal en un espacio geográfico sufre alteraciones, experimenta una pérdida de confort térmico; en suma, el clima cambia. En este aumento de las temperaturas

10 Vid. Quereda Sala et alii (2001) Nuestro porvenir climático, ¿Un escenario de aridez?. Universitat Jaume I, Castellón, 224 p. 
mínimas puede jugar el efecto urbano de calor y también, en las localidades de costa, el calentamiento que experimenta el mar Mediterráneo desde hace dos décadas en los meses de verano, tal y como confirman las termografías de satélite. En efecto, desde mediados de los años noventa del siglo XX, la cuenca occidental del Mediterráneo se calienta antes (junio) y más (la temperatura superficial marina llega a alcanzar picos de $27-28^{\circ} \mathrm{C}$ ) en el calendario anual; es decir se calienta más y un número mayor de semanas al año de lo que lo hacía en los años ochenta (López García, 1991) ${ }^{11}$. Este colchón estival de aguas calientes eleva la humedad ambiental, frena el descenso nocturno de la temperatura e incrementa, en suma, la sensación térmica.

El estudio sobre «Proyecciones climáticas para el siglo XXI» (Aemet, 2015), actualización de las proyecciones elaboradas en 2011, ha manejado tres variables (temperatura máxima, temperatura mínima y precipitación) en el análisis de la evolución modelizada del clima en España para las próximas décadas. Los resultados vienen a confirmar los datos apuntados en informes anteriores de la propia Agencia Estatal y de la Oficina Española de Cambio Climático. Para el conjunto peninsular, el incremento en las temperaturas máximas en 2100 se estima entre $1^{\circ}$ y $7^{\circ} \mathrm{C}$ para diferentes escenarios de emisión de gases; en las temperaturas mínimas el aumento se cifra entre $1^{\circ}$ y $6^{\circ} \mathrm{C}$; y, por su parte, las precipitaciones se reducirían entre un 4 y $8 \%$ respecto a las medias del período 1961-2000 2005 , con un margen de incertidumbre del $10 \%$.

Es interesante destacar los valores de diferentes variables térmicas y pluviométricas calculados en este informe, con horizonte en el año 2100, para las regiones del litoral mediterráneo, objeto principal de nuestro estudio, puesto que de su evolución futura va a depender la planificación de la temporada turística y la propia planificación hidrológica, básica para la garantía de suministro a las áreas turísticas de este gran espacio regional. La tabla resume los valores de cambio en las variables climáticas para los territorios de la fachada mediterránea peninsular (vid. tabla 1).

A efectos de confort climático en áreas turísticas del litoral mediterráneo es significativo el aumento que se prevé en el número de días cálidos, de noches cálidas y en la duración de las olas de calor en todas las regiones del mediterráneo español. Se trata de variables que, unidas a valores normales de humedad atmosférica altos, se relacionan con la génesis de sensaciones térmicas de alto disconfort. Y a ello hay que sumar el señalado calentamiento de las aguas del Mediterráneo occidental en los meses cálidos del año que ha experimentado un aumentos en los últimos años prolongando, asimismo, el período de temperaturas elevadas $\left(<25^{\circ} \mathrm{C}\right)$ entre junio y septiembre. Para el conjunto de la cuenca del Mediterráneo, se ha estimado un incremento absoluto de $0,22^{\circ} \mathrm{C}$ por década, desde 1973 a 2008 (Skliris et al., 2012). Por su parte, Miro Pérez (2014) a partir del uso de datos de satélite pertenecientes a la base de datos de la NOAA/NASA AVHRR Oceans Pathfinder, ha calculado el incremento térmico en las aguas del litoral próximo a la Comunidad Valenciana, para el período 1985-2007, estimando una pendiente anual por década de $0,26^{\circ} \mathrm{C}$ de incremento (vid. tabla 2). Como indica Miró Pérez, lo más significativo de su análisis es que la responsabilidad del calentamiento recae especialmente en los meses

11 Vid. López García, Ma . J. (1991) La temperatura del mar Balear a partir de imágenes de satélite. Universidad de Valencia, $158 \mathrm{pp}$. 
de primavera e inicio del verano (abril a junio) y, en menor medida, en octubre. De este modo se confirma la tendencia no sólo al aumento de temperatura de las aguas del mar en los meses centrales del verano, sino a la prolongación señalada del período anual con aguas cálidas frente a las costas del litoral mediterráneo español.

\section{Tabla 1}

\section{CAMBIOS EN LAS VARIABLES CLIMÁTICAS PRINCIPALES ${ }^{12}$ DE LAS REGIONES DEL MEDITERRÁNEO ESPAÑOL (HORIZONTE 2100)}

\begin{tabular}{|c|c|c|c|c|c|}
\hline & CATALUNA & BALEARES & C. VALENCIANA & MURCIA & ANDALUCÍA \\
\hline $\mathrm{T}^{\mathrm{a}}$ máxima $\left({ }^{\circ} \mathrm{C}\right)$ & $+1.5 \mathrm{a}+5.5$ & $+2.5 \mathrm{a}+5.5$ & $+1 \mathrm{a}+5$ & $+2 \mathrm{a}+5$ & $+2.5 \mathrm{a}+5.5$ \\
\hline Duración olas de calor (días) & $10-35$ & $10-25$ & $5-35$ & $10-45$ & $7-27$ \\
\hline Días cálidos (\%) & $20-50$ & $25-55$ & $15-50$ & $20-55$ & $20-50$ \\
\hline $\mathrm{T}^{\mathrm{a}}$ mínima ( $\left.{ }^{\circ} \mathrm{C}\right)$ & $+2.5 \mathrm{a}+5.5$ & $+2 \mathrm{a}+5$ & $+1 \mathrm{a}+4.5$ & $+2.5 \mathrm{a}+4.5$ & $+2 \mathrm{a}+4.5$ \\
\hline $\begin{array}{c}\text { Días de heladas (días) } \\
\text { Noches cálidas (\%) }\end{array}$ & $-20 \mathrm{a}-35$ & 0 & $-5 \mathrm{a}-8$ & $-3 \mathrm{a}-7$ & $-5 \mathrm{a}-7$ \\
\hline $\begin{array}{c}\text { Cambio volumen } \\
\text { precipitación (\%) }\end{array}$ & $0 \mathrm{a}+5$ & $-5 \mathrm{a}-10$ & $0 \mathrm{a}-10$ & $0 \mathrm{a}-5$ & $-7 \mathrm{a}-15$ \\
\hline $\begin{array}{c}\text { Cambio precipitaciones } \\
\text { intensas }(\%)\end{array}$ & $0 \mathrm{a}-5$ & $0 \mathrm{a}-2.5$ & $0 \mathrm{a}-7$ & $+1 \mathrm{a}-1$ & $+2 \mathrm{a}-5$ \\
\hline $\begin{array}{c}\text { Duración períodos secos } \\
\text { (días) }\end{array}$ & 0 & $0 \mathrm{a}+2$ & $0 \mathrm{a}+2$ & $0 \mathrm{a}+2.5$ & $+2 \mathrm{a}+4$ \\
\hline \begin{tabular}{c}
$\mathrm{N}^{\mathrm{a}}$ días de lluvia (días) \\
\hline
\end{tabular} & $+2 \mathrm{a}+10$ & -5 & $-2 \mathrm{a}+5$ & $-2.5 \mathrm{a}+2.5$ & -5 \\
\hline
\end{tabular}

Fuente: AEMET. Proyecciones climáticas para el s. XXI. Elaboración propia.

Tabla 2

\section{INCREMENTO DE TEMPERATURA EN LAS AGUAS DEL MEDITERRÁNEO OCCIDENTAL FRENTE A LA COMUNIDAD VALENCIANA (1985-2007)}

\begin{tabular}{|c|c|c|}
\hline & $\begin{array}{c}\text { Pendiente Sen en } \\
{ }^{\mathbf{}} \mathbf{C} / \text { década }\end{array}$ & $\begin{array}{c}\text { Magnitud absoluta de cambio entre 1985 } \\
\mathbf{y} \text { 2007 (según pendiente Sen) en }{ }^{\mathbf{}} \mathbf{C}\end{array}$ \\
\hline ENERO & 0.16 & 0.36 \\
\hline FEBRERO & 0.17 & 0.39 \\
\hline MARZO & 0.21 & 0.47 \\
\hline ABRIL & 0.54 & $\mathbf{1 . 2 4}$ \\
\hline MAYO & 0.68 & $\mathbf{1 . 5 7}$ \\
\hline JUNIO & 0.68 & $\mathbf{1 . 5 7}$ \\
\hline
\end{tabular}

12 La interpretación de estas variables se encuentra en: http://www.aemet.es/es/serviciosclimaticos/cambio_climat/result_graficos/ayuda. (Consultado en junio 2015). 


\begin{tabular}{|c|c|c|}
\hline JULIO & 0.40 & 0.92 \\
\hline AGOSTO & 0.11 & 0.25 \\
\hline SEPTIEMBRE & -0.11 & -0.26 \\
\hline OCTUBRE & 0.21 & 0.49 \\
\hline NOVIEMBRE & 0.08 & 0.18 \\
\hline DICIEMBRE & 0.07 & 0.16 \\
\hline A $\tilde{\mathbf{N O}}$ & $\mathbf{0 . 2 6}$ & $\mathbf{0 . 6 1}$ \\
\hline
\end{tabular}

Fuente: Miró Pérez, 2014.

A efectos de planificación y adaptación de los espacios turísticos del litoral mediterráneo ante las consecuencias del cambio climático, estos datos de proyección futura de valores atmosféricos y de temperatura de aguas marinas suponen:

- La posibilidad de modificar el calendario de temporada alta turística que podrá prolongarse desde junio a septiembre sin solución de continuidad, además de considerar los meses de mayo y octubre muy aptos para las estancias turísticas en este espacio geográfico.

- La necesidad de acondicionamiento climático de los establecimientos turísticos, y en general de las viviendas residenciales, a una situación más habitual de altas temperaturas y elevada humedad, diurna y nocturna, a los efectos de compensar el disconfort térmico que se estima creciente en los espacios costeros, especialmente a partir de 2050 .

- La obligación de tener bien diseñados los sistemas de abastecimiento de agua, a escala regional y local, en un área con natural escasez de recursos, donde la propia reducción de precipitaciones, el aumento de la irregularidad en su desarrollo y el incremento de la evaporación en embalses, originará una disminución de volúmenes de agua superficial disponible. Esto será más manifiesto en los territorios del centro y sur del litoral mediterráneo español.

- La necesidad, asimismo, de modificar, en la escala local, los protocolos de protección civil y sanidad pública, puesto que se van a alterar los calendarios de riesgo frente a determinados peligros de causa climática (tormentas y lluvias intensas por la presencia de aguas calidad en el Mediterráneo occidental durante un período del año mayor), así como la frecuencia e intensidad de aparición de extremos térmicos (olas de calor y sus efectos en grupos de riesgo).

En estrecha relación con el comportamiento térmico del agua del mar está el efecto del calentamiento en la subida del nivel de mar y su afección a las áreas litorales. Desde 2002, el grupo de Ingeniería Oceanográfica y de Costas de la Universidad de Cantabria se desarrolla el proyecto $\mathrm{C} 3 \mathrm{E}$ (Impacto del cambio climático en la costa española ${ }^{13}$ ),

13 Este proyecto integra 3 fases: Fase I, Evolución de cambios en la dinámica costera española; Fase II, Evaluación de efectos en la costa española; y Fase III, Estrategias frente al cambio climático en la costa. (Vid. Losada et. al., 2014). 
financiado por el Ministerio de Medio Ambiente, que ha ido enriqueciéndose, en método y resultados, a lo largo de sus diversas fases de ejecución. En 2014 se han hecho públicos los resultados de la tercera fase de este proyecto y se apuntan los siguientes datos, a tener en cuenta para la adaptación futura de los espacios costeros en España:

- Al igual que pasa en el resto del mundo, en España los impactos observados atribuibles al cambio climático son aquellos que corresponden a cambios en la temperatura del océano o a la acidificación. Con la información existente, los impactos observados relativos a inundación o erosión en zonas costeras no son atribuibles a cambio climático pues están altamente afectados por la acción del ser humano.

- El oleaje es una de las principales dinámicas susceptibles de cambio que afectan a nuestra costa. En los últimos años se han observados aumentos en la intensidad del oleaje en el Cantábrico y disminución en el Mediterráneo y Canarias.

- El aumento del nivel del nivel medio del mar en la zona Atlántico-Cantábrica sigue la tendencia media global observada entre 1,5 y 1,9 mm/año entre 1900 y 2010 y de entre 2,8 mm/año y 3,6 mm/año entre 1993 y 2010. Sin embargo, existe una mayor incertidumbre en cuanto al nivel medio del mar en el Mediterráneo por efectos regionales.

- Considerando un escenario tendencial de aumento de nivel del mar a 2040 (aproximadamente $6 \mathrm{~cm}$ ), las playas de la cornisa cantábrico-atlántica y norte de las Canarias experimentarán retrocesos medios cercanos a los 3 metros, 2 metros en el Golfo de Cádiz y valores medios entre 1 y 2 metros en el resto de las fachadas.

Un factor que, sin duda, va a influir en el grado de riesgo de la costa española frente al cambio climático es la ocupación humana del litoral, que ha experimentado un crecimiento importante en las dos últimas décadas. El ritmo de crecimiento anual de la población residente en municipios costeros fue de un 1,9\%, siendo superior en la fachada mediterránea, especialmente en Tarragona, Girona, Alicante y Castellón. Esto ha traído consigo cambios importantes en los usos del suelo, produciéndose un crecimiento urbanístico descontrolado en muchas áreas de la costa española, especialmente en el litoral mediterráneo, que ha culminado con una «artificialización» rotunda de este espacio geográfico.

Por su parte, la proyección de retroceso de las playas en la costa española para 2040, si se cumplen las previsiones climáticas establecidas en los modelos del IPCC, se estiman retrocesos de playa de hasta 3 metros en la zona atántico-cantábrica; de $2 \mathrm{~m}$. en el Golfo de Cádiz, y de 1,5 a 2 m. en el litoral mediterráneo. Por su parte, la cota de inundación seguirá una tendencia al alza y se prevén un aumento del $8 \%$ en la fachada norte de la costa española y el Mar de Alborán para el año 2040 (lo que supone en torno a $20 \mathrm{~cm}$ más de cota de inundación). El sur-sureste de las Islas Canarias muestran aumentos en torno al $6 \%$ y el Golfo de Cádiz y resto del litoral Mediterráneo presenta aumentos en torno al 2-3\% para el año 2040.

Por último, el informe $\mathrm{C} 3 \mathrm{E}$ hace una valoración económica de las pérdidas que se podrían generar en la costa española como efecto de la subida del nivel del mar, perdida 
de las playas e incremento de la cota de inundación en el litoral y llega a la conclusión siguiente: «Si la sociedad actual se viera enfrentada a la subida del nivel del mar considerada para el año 2100, sin incorporar medidas de adaptación, el valor acumulado de las pérdidas futuras alcanzaría cifras entre 500 y 4.000 millones de euros, lo que supone cifras de entre el 0,5\% y el 3\% del PIB anual según las provincias y los escenarios» (Losada et. al., 2014).

Una valoración actualizada del impacto económico del cambio climático y, de manera específica, de sus efectos en áreas geográficas de litoral con vocación turística, como el litoral mediterráneo español, ha sido realizada en la revisión del informe JRC Peseta II (2014). A partir del manejo de 4 modelos climáticos se ha calculado el efecto en diversos sectores económicos del calentamiento planetario. En efecto, se han manejado tres escenarios de emisiones medio-altas: uno sin medidas de mitigación (SRES A1B) o business as usual, que conduce a un aumento global de $3,5^{\circ} \mathrm{C}$ de temperatura en 2100 , en comparación con el nivel preindustrial; un segundo escenario a partir también del SRES A1B más cálido y más seco; un tercer escenario, por el contrario, más frío y húmedo que el de referencia SRES A1B. Por último, un cuarto escenario que tiene en cuenta el objetivo climático de la UE de incremento tan sólo de $2^{\circ} \mathrm{C}$ en 2100 , con reducción de emisiones, a partir del modelo ENSEMBLES E1. España se ha incluido en la región de Europa meridional dentro de este informe, para la cual se presenta una evolución poco favorable en los registros de temperatura y de precipitación para el último tercio del presente siglo, incluso en el modelo con reducción de emisiones $\left(2^{\circ} \mathrm{C}\right.$ model $)$ (vid. tabla 3$)$.

Tabla 3

EVOLUCIÓN DE LAS TEMPERATURAS Y LAS PRECIPITACIONES EN EUROPA MERIDIONAL, HORIZONTE 2070-2100, RESPECTO AL PERÍODO 1961-1990

\begin{tabular}{|c|c|c|c|c|}
\hline & $\begin{array}{c}\text { Modelo } \\
\text { business as } \\
\text { usual }\end{array}$ & $\begin{array}{c}\text { Modelo } \\
\text { business as } \\
\text { usual (variante } \\
\text { cálida) }\end{array}$ & $\begin{array}{c}\text { Modelo } \\
\text { business as } \\
\text { usual (variante } \\
\text { fría) }\end{array}$ & Modelo $2^{\circ} \mathrm{C}$ \\
\hline Temperatura $\left({ }^{\circ} \mathrm{C}\right)$ & +3.2 & +3.7 & +2.4 & +2.3 \\
\hline $\begin{array}{c}\text { Precipitaciones } \\
(\%)\end{array}$ & -19 & -14 & -14 & -14 \\
\hline
\end{tabular}

Fuente: JRC-PESETA II project (2014).

En la actualidad resulta difícil negar el actual ciclo de calentamiento planetario que, como se ha señalado (vid. supra) ya no encuentra explicación por causas sólo naturales (variaciones en la radiación solar). Siguen quedando, sin embargo, incertidumbres en el comportamiento de algunos elementos climáticos, especialmente en la precipitación, cuya modelización es compleja; en la actualidad, numerosas regiones del mundo -entre ellas, España- no manifiestan tendencias claras en este elemento climático. Esto nos recuerda 
que los modelos de cambio climático no son predicciones, al estilo de la predicción meteorológica diaria realizada en los servicios meteorológicos de los Estados. Tan sólo marcan tendencias, pero ahí estriba su valor. Si las tendencias que muestran resultan poco cambiantes con el paso del tiempo, como ocurre con los modelos climáticos incluidos en los diferentes informes de cambio climático realizados por el IPCC desde 1990, entonces la probabilidad de que se cumplan es elevada. Por ello, la próxima década es decisiva para confirmar las actuales hipótesis de trabajo del IPCC y mejorar, aún más, la modelización climática para alcanzar escalas de detalle (local scale). Ahora bien, la necesidad de mantener la investigación climática con el fin de ir confirmando todos los extremos de la hipótesis principal de trabajo (efecto invernadero de origen antrópico) no debe significar inacción de las administraciones públicas o de los agentes privados en las medidas de mitigación y adaptación que deben aplicarse en los territorios.

\section{POLÍTICAS DE MITIGACIÓN Y ADAPTACIÓN AL CAMBIO CLIMÁTICO EN EL LITORAL MEDITERRÁNEO ESPAÑOL}

La mitigación y adaptación ante el cambio climático debe entenderse como el conjunto de actuaciones puestas en marcha para adecuar los territorios y las actividades que en ellos se dan a la nueva realidad climática que se proyecta para las próximas décadas. Si, como se ha señalado, se cumplen las previsiones de la modelización climática llevada a cabo por organismos internacionales y centros de investigación climática, los territorios y las sociedades que en ellos viven experimentarán alteraciones en sus modos de vida actuales, positivas en algunos casos y negativas en otros, según sus rasgos climáticos actuales, para las que resulta conveniente tener previstos mecanismos de adaptación que deben ir planteándose desde este momento, debido al rasgo de proceso de medio y largo plazo del propio cambio climático.

Es interesante destacar que en materia de mitigación del cambio climático en los países occidentales se ha pasado de las acciones de «lucha» contra el proceso, basadas, casi en exclusiva, en aspectos energéticos (cambio de modelo, apuesta por energías limpias) a concepciones más integrales donde, junto a esta cuestión, cuenta el territorio y sus actividades como principio motor de las actuaciones a llevar a cabo. En este contexto es donde la adaptación cobra protagonismo como mecanismo multidisciplinar y multitarea para el planteamiento de soluciones integrales ante un problema global en escalas menores (regional y local).

Como se ha señalado, hay actividades económicas con un grado de exposición alto a los efectos del cambio climático, como la agricultura y el turismo; en este segundo caso y para algunas modalidades de gran uso social (sol y playa, nieve) se une, además, una vulnerabilidad elevada debido al volumen elevado de personas que lo practican. El turismo es pues una actividad vulnerable que debe adaptarse a la nueva realidad climática que se proyecta (Olcina, 2012).

El escenario de cambio climático futuro obliga a los destinos turísticos y a sus agentes implicados (administración pública, empresas y usuarios) a adaptarse a la nueva realidad si se quiere mantener la actual competitividad. Se trata de un proceso de medio y largo plazo que debe comenzar a planificarse ahora para evitar mayores costes económicos, 
sociales y territoriales dentro de unas décadas. En los últimos años se han desarrollado acciones de mitigación y adaptación de la actividad turística ante el cambio climático en diversos países del mundo y, entre ellos también en España y en alguna de sus comunidades autónomas. Por lo general, las actuaciones orientadas a la lucha contra el cambio climático se han orientado, sobre todo, a las cuestiones energéticas, y han tenido menor protagonismo el desarrollo de medidas de tipo económico (tasas ambientales) y territorial (planificación sostenible).

La relación de documentos oficiales existentes en España y en sus Comunidades Autónomas que incluyen aspectos de la relación cambio climático-actividad turística es variada e incluye:

- Plan Nacional de Adaptación al Cambio Climático

- Planes estatales sectoriales para el sector turístico (p.e. eficiencia energía)

- Planes autonómicos de adaptación al cambio climático

- Planes autonómicos de política turística general con mención al cambio climático.

Y a ello se suman las acciones que, desde el ámbito privado, han puesto en marcha las empresas turísticas en los últimos años dentro de sus políticas de mitigación de los efectos del cambio climático.

\subsection{Plan Nacional de Adaptación al Cambio Climático}

El Gobierno español, siguiendo el ejemplo del resto de países europeos, puso en marcha, en 2006, el Plan Nacional de Adaptación al Cambio Climático (PNACC), a propuesta de Oficina Española de Cambio Climático y de la Secretaría General para la prevención de la contaminación y del Cambio Climático del Ministerio de Medio Ambiente, con los siguientes objetivos:

- desarrollar los escenarios climáticos regionales para la geografía española.

- desarrollar y aplicar métodos y herramientas para evaluar los impactos, vulnerabilidad y adaptación al cambio climático en diferentes sectores socioeconómicos y sistemas ecológicos en España.

- aportar al esquema español de I+D+i las necesidades más relevantes en materia de evaluación de impactos del cambio climático.

- realizar un proceso continuo de actividades de información y comunicación de los proyectos Plan Nacional de Adaptación al Cambio Climático.

- promover la participación entre todos los agentes implicados en los distintos sectores y sistemas, con objeto de integrar en las políticas sectoriales la adaptación al cambio climático.

- elaborar informes específicos con los resultados de las evaluaciones y proyectos.

- elaborar informes periódicos de seguimiento y evaluación de los proyectos y del conjunto del Plan Nacional de Adaptación. 
Para el diseño de políticas y medidas de actuación este Plan se basó en los resultados del informe sobre «Evaluación preliminar del Cambio Climático en España», elaborado en los primeros años del nuevo siglo y editado en 2005 por el Ministerio de Medio Ambiente. Sorprendentemente este Informe no ha merecido actualización en años posteriores. Eso sí, la Oficina Española de Cambio Climático y la Agencia Estatal de Meteorología, como se ha señalado (vid. supra) ha ido actualizando las proyecciones climáticas para España en los últimos años; y, asimismo, el proyecto proyecto $\mathrm{C} 3 \mathrm{E}$ (Impacto del cambio climático en la costa española) ha ido ofreciendo resultados, -texto y cartografía- de la modelización realizada (vid. supra). Sería, sin embargo, necesaria una actualización regular de los diferentes apartados que se incluían en el citado informe, al estilo de lo que se lleva a cabo en algunas Comunidades Autónomas, como Cataluña o el País Vasco.

En relación con el análisis de los impactos del cambio climático en el sector turístico español el capítulo sobre los «Impactos sobre el sector turístico» incluido en el mencionado informe elaborado por Esteban, López Palomeque y Aguiló ${ }^{14}$, sigue siendo una referencia básica. En él se aborda, desde el realismo y la sensatez, la situación de la actividad turística, su impacto sobre la economía española, la sensibilidad de la actividad turística al clima actual y los impactos previsibles del cambio climático a partir de la modelización regionalizada elaborada por Aemet y la Oficina Española de Cambio Climático. Se señalan también las modalidades turísticas más vulnerables (litoral y de montaña) ante los futuros escenarios climáticos y se incluyen una serie de medidas de adaptación del sector turístico ante el cambio climático (cambios en la estacionalidad -sol y playa-, cambios en algunos productos turísticos -nieve-; cambios en la preferencias de los turistas y en la toma de decisiones empresariales, entre otros). Se establecen, por último, una serie de indicadores de seguimiento para la detección del cambio climático, adaptados a las diferentes modalidades turísticas del territorio español. Un apartado final de este informe señala, con acierto, las incertidumbres existentes en materia de cambio climático y turismo en España y aconseja una serie de líneas de investigación futuras en este tema que, desde el momento de elaboración del informe, apenas se han desarrollado por la administración y en grado muy escaso por el empresariado del sector.

Con arreglo a estas pautas, el Plan Nacional de Adaptación al Cambio Climático ha incluido las siguientes medidas y acciones en materia turística:

- Evaluación del papel del clima actual en el sistema turístico español y los impactos que supondría el cambio climático por zonas y productos más vulnerables, integrando las diferentes escalas de manifestación del fenómeno.

- Cartografía de zonas críticas y vulnerables para el turismo, bajo distintos escenarios de cambio climático.

14 Vid. Esteban, A., López Palomeque, F. y Aguiló, E. (2005) «Impactos sobre el sector turístico», en Impactos del Cambio Climático en España, Ministerio de Medio Ambiente, Oficinal Española de Cambio Climático, Madrid, 653-690 p. 
- Desarrollo de sistemas de indicadores sobre la relación cambio climático-turismo para su medición y detección.

- Desarrollo de modelos de gestión para optimizar las principales opciones adaptativas y las implicaciones en las políticas turísticas.

- Evaluación de los potenciales impactos del cambio climático en el patrimonio cultural (tangible e intangible) y su repercusión en el turismo

Estas acciones en materia turística es uno de los aspectos menos desarrollados del Plan Nacional de Adaptación al Cambio Climático que, sin embargo, se ha beneficiado para el planteamiento de escenarios de futuro -asimismo, por elaborar- de los resultados alcanzados en las modelizaciones climática y de la costa española. En el Tercer Informe de Seguimiento del PNACC (2014) se señala que tan sólo se ha completado un estudio sobre el impacto del cambio climático en el turismo interior español, pero ni se ha elaborado un análisis de dicho impacto en el turismo de sol y playa, el de mayor importancia económica y social en nuestro país, ni tampoco del impacto en el turismo de nieve, actividad de importancia creciente en los últimos años, ni tampoco se ha llevado a cabo una valoración integral del impacto del cambio climático en el sector turístico que debería servir como punto de partida para el desarrollo de programas y acciones concretas de adaptación en los próximos años.

\subsection{Planes estatales sectoriales con incidencia en la actividad turística}

Para impulsar las medidas de lucha contra el cambio climático, dentro de un programa general de mejora del medio ambiente (Planes PIMA de Impulso al Medio Ambiente) desarrollado entre 2014 y 2015, el gobierno ha aprobado un plan específico para la adaptación al cambio climático, el Plan PIMA-Adapta, que integra un conjunto de medidas concretas, de tipo estructural, a desarrollar en la costa española, en el dominio hidráulico y en los parques nacionales. En total son 46 actuaciones, con un presupuesto de 12 millones de $€$, que supone un cambio en la actitud del gobierno conservador de España que hasta este momento había minusvalorado las acciones contra el cambio climático, rompiendo una estrategia de actuación en esta cuestión desarrollada desde 2004. En síntesis es un programa tímido de medidas que contempla actuaciones de regeneración de playas, estabilización de taludes y dunas, aportación de arenas, restauración hidrológico-forestal, obras menores de defensa de avenidas y monitorización de cambio de especies de vegetación en parques nacionales. Tal vez, el mayor interés de este plan radica en la asignación de presupuesto para estudios de evolución de la línea de costa y de evaluación de riesgos asociados al cambio climático a escala provincial. En definitiva se trata de un plan muy modesto si se compara con las iniciativas que se están llevando a cabo en el contexto europeo.

En relación con el desarrollo de medidas de eficiencia energética en el sector turístico, España puso en marcha, hasta 2012, el Plan-E, con una aplicación especial en la actividad turística (Futur-E Turismo, 2009 a 2011), donde se contemplaban una serie de ayudas económicas para la mejora de la eficiencia energética de las instalaciones turísticas, el ahorro de energía y de agua y la implantación de nuevas tecnologías y sistemas de cali- 
dad, entre otros aspectos. En el último informe aprobado por la Secretaria de Estado de Cambio Climático, en julio de $2011^{15}$, se señalaba que «con la puesta en marcha de los planes Futures y Renove (un programa para revitalizar las instalaciones turísticas) se ha puesto a disposición del sector en dos años 1.900 millones de euros con los que se han financiado 6.830 proyectos en las diecisiete Comunidades Autónomas, generando una inversión inducida de 3.600 millones de euros».

El materia de política turística estatal el principal instrumento es el Plan Nacional e Integral de Turismo, 2012-2015, que se sustenta, según sus propios argumentos, en una visión general del sector turístico, para hablar de una nueva etapa, centrada en la innovación y nuevos modelos de gestión, donde en el diagnóstico se llega a señalar la salud del cliente y su relación con el entorno, pero en el que no hay una sola referencia a la posible incidencia del cambio climático como factor global.

Este Plan contiene referencias a la sostenibilidad de la actividad y a las acciones para llevarla a cabo, en colaboración con otras administraciones, para que pueda aplicarse en los destinos y recursos turísticos. En este sentido, las actuaciones que se han llevado a cabo desde la administración pública y desde el propio ámbito empresarial del sector turístico, han hecho énfasis sobre todo en la eficiencia energética. Otra medida que aparece es la de definir un sistema de indicadores para los sistemas de certificación, que permita medir de una forma fiable y operativa tanto la huella de $\mathrm{CO}$ en el turismo como su reducción, fruto de la aplicación de los sistemas de certificación y de establecer un marco favorable para las empresas asociadas a la compensación de huella de $\mathrm{CO}$, fomentando modelos de negocio que establezcan lazos con el sector turístico. Más allá de este aspecto, ni en los programas ni en las medidas a aplicar hay acciones o líneas concretas relativas al cambio climático y a sus posibles efectos en este sector.

\subsection{Planes autonómicos de adaptación al cambio climático}

La inexistencia de referencias al tema del cambio climático en la política turística del país, obliga a comprobar si existe esta preocupación en los gobiernos autonómicos, a los que corresponden las competencias en materia de ordenación del turismo. Con esta finalidad, se han revisado los instrumentos vigentes en materia de política turística de las comunidades autónomas mediterráneas, por la importancia estratégica que el turismo tiene en las estructuras regionales.

Para fundamentar estrategias de adaptación al cambio climático en las escalas regional y local escala local existen en España una serie de herramientas cuya consulta y seguimiento, a la hora de actualizar dichas acciones, es necesario abordar (vid. tabla 4).

Las Comunidades Autónomas han desarrollado también planes y estrategias de adaptación al cambio climático, en los que la cuestión energética (reducción de emisiones, energías alternativas) ocupa la porción principal de las acciones programadas. En el ámbito del litoral mediterráneo, todas sus Comunidades Autónomas han desarrollado este tipo de estrategias, que en algún caso (Cataluña) se acompaña de la elaboración periódica de un

15 La Secretaría de Estado de Cambio Climático dejó de funcionar en noviembre de 2011, tras la victoria del Partido Popular en las elecciones generales celebradas en España. 
completo informe sobre el estado del cambio climático y su modelización futura en el territorio de referencia. Para la adaptación de la actividad turística hay previstas una serie de actuaciones en cada región, que se vinculan a la promoción de destinos sostenibles, la incentivación de medidas de ahorro (energía, agua) en establecimientos hoteleros, las acciones de formación del personal y de información a los clientes de las instalaciones turísticas en las cuestiones de sostenibilidad. En general se trata de acciones que persiguen la diversificación del producto turístico y la apuesta por la sostenibilidad como principio de actuación en la búsqueda de la calidad de los destinos, más que de medidas concretas de adaptación al cambio climático. La tabla adjunta resumen las acciones de adaptación previstas en los planes regionales de cambio climático del litoral mediterráneo español (vid. tabla 5).

Tabla 4

HERRAMIENTAS DE CONSULTA PARA EL DISEÑO DE ESTRATEGIAS Y MEDIDAS DE ADAPTACIÓN AL CAMBIO CLIMÁTICO EN LAS ESCALAS REGIONAL Y LOCAL

\begin{tabular}{|c|c|}
\hline MODELOS CLIMÁTICOS & $\begin{array}{l}\text {-Informes del IPCC }\left(5^{\circ} \text { informe, } 2013.14\right) \\
\text {-Modelización de escenarios climáticos } \\
\text { (AEMET, renovación regular) }\end{array}$ \\
\hline $\begin{array}{l}\text { MODELOS PLUVIO- } \\
\text { HIDROLÓGICOS }\end{array}$ & $\begin{array}{l}\text {-Modeliización de evolución de precipitaciones } \\
\text { y volumenes de agua disponibles (CEDEX, } \\
\text { 2012) } \\
\text {-Informes de Demarcaciones Hidrográficas (en } \\
\text { cumplimiento de la Directiva 60/2000) } \\
\text {-Sistema Nacional de Cartografía de Zonas } \\
\text { Inundables (SNCZI) } \\
\text {-Cartografía de inundaciones de las CC: AA. } \\
\text {-Planes de Gestión de Inundaciones } \\
\text { (Demarcaciones Hidrográficas) }\end{array}$ \\
\hline $\begin{array}{l}\text { MODELOS DE GASTO DE } \\
\text { AGUA }\end{array}$ & $\begin{array}{l}\text {-Planes de Gestión de Sequía (Demarcaciones } \\
\text { Hidrográficas o Agencias Autonómicas del } \\
\text { Agua) }\end{array}$ \\
\hline $\begin{array}{l}\text { MODELOS DE EFECTOS EN EL } \\
\text { LITORAL }\end{array}$ & $\begin{array}{l}\text {-Proyecto I3C de efectos del cambio climático } \\
\text { en la costa española }\end{array}$ \\
\hline $\begin{array}{l}\text { MODELOS DE IMPACTO } \\
\text { ECONÓMICO }\end{array}$ & $\begin{array}{l}\text {-Informe JRC PESETA (II informe 2014) } \\
\text {-Informes sectoriales de efectos del cambio } \\
\text { climático (agricultura, turismo) }\end{array}$ \\
\hline
\end{tabular}

Fuente: Elaboración propia. 


\section{Tabla 5 \\ MEDIDAS DE ADAPTACIÓN DEL SECTOR TURÍSTICO AL CAMBIO CLIMÁTICO CONTEMPLADAS EN LOS PLANES AUTONÓMICOS DE ADAPTACIÓN AL CAMBIO CLIMÁTICO DEL LITORAL MEDITERRÁNEO ESPAÑOL}

\begin{tabular}{|c|c|}
\hline CC.AA & ACCIONES DESTACADAS \\
\hline Cataluña & $\begin{array}{l}\text {-Impulsar la desestacionalización de la oferta turística (potenciar la } \\
\text { estación bimodal: primavera y otoño) y de la demanda (cambios en } \\
\text { el calendario escolar). } \\
\text {-Incorporar los impactos previstos del cambio climático en el Plan } \\
\text { estratégico del turismo, así como las medidas de adaptación } \\
\text { propuestas. } \\
\text {-Impulsar el ahorro y la eficiencia en el uso del agua (separación de } \\
\text { aguas grises, depósitos de pluviales, etc.) y de la energía. }\end{array}$ \\
\hline Baleares & $\begin{array}{l}\text {-Implantación de políticas empresariales de uso eficiente de la } \\
\text { energía. } \\
\text {-Incorporación de un estudio de emisiones de CO2 y de medidas } \\
\text { correctoras en la solicitud de la licencia } \\
\text { integrada de actividades para los establecimientos comerciales. } \\
\text {-Fomento de la utilización de dispositivos y mecanismos de control } \\
\text { eficientes para establecimientos turísticos de alojamiento. } \\
\text {-Buenas prácticas en medio ambiente en el sector turístico. } \\
\text {-Normativa para el ahorro de energía y disminución de emisiones de } \\
\text { gases de efecto invernadero en el sector turístico de alojamiento. }\end{array}$ \\
\hline C. Valenciana & $\begin{array}{l}\text { - Refuerzo de la sostenibilidad como eje de las estrategias de } \\
\text { desarrollo turístico de la Comunitat Valenciana a corto, medio y largo } \\
\text { plazo. } \\
\text { - Apoyo al sector turístico para la implantación de sistemas de gestión } \\
\text { medioambiental y la mejora de la eficiencia energética en empresas } \\
\text { y entidades locales turísticas y para el planeamiento y desarrollo } \\
\text { sostenible de destinos turísticos. } \\
\text {-Inversión en infraestructuras y equipamientos sostenibles en } \\
\text { empresas turísticas y entidades locales. }\end{array}$ \\
\hline Murcia & $\begin{array}{l}\text {-Fomento del consumo responsable en el sector turístico } \\
\text {-Fomentar el ahorro y la eficiencia energética en el sector: } \\
\text {-Fomentar la utilización de vehículos de alquiler más eficientes, de } \\
\text { menores emisiones de GEI. } \\
\text {-Plan para fomentar el uso de la microgeneración. } \\
\text {-Plan de sustitución de equipos de climatización por otros más } \\
\text { eficientes: tecnología «inverter». }\end{array}$ \\
\hline
\end{tabular}




\begin{tabular}{|c|l|}
\hline \multirow{7}{*}{ Murcia } & $\begin{array}{l}\text {-Desarrollo de modelos ecoturísticos } \\
\text {-Promocionar los modelos de turismo rural, cultural y deportivo entre } \\
\text { otros, que sean sostenibles y respetuosos con el medio en el que se } \\
\text { desarrollan. } \\
\text {-Fomento de la red de itinerarios y senderos ecoturísticos. } \\
\text {-Desestacionalización de la oferta para evitar la concentración y la } \\
\text { sobreexplotación de los recursos en determinadas épocas del año. } \\
\text {-Diversificación de la oferta turística. } \\
\text {-Aumento de la dotación de servicios de tipo social, cultural, } \\
\text { sanitario, deportivo y comercial en zonas turísticas. }\end{array}$ \\
\hline Andalucía & $\begin{array}{l}\text {-Realizar planes de reconversión para la adaptación de los espacios de } \\
\text { alta montaña a las nuevas condiciones climáticas. } \\
\text {-Realizar estudios de detalle sobre el retroceso de playas por aumento } \\
\text { del nivel medio del mar y su incidencia en los destinos turísticos de } \\
\text { sol y playa. } \\
\text {-Adaptar el entorno físico urbano y la infraestructura turística en las } \\
\text { ciudades de atractivo monumental y cultural. } \\
\text {-Adecuar progresivamente las edificaciones e infraestructuras } \\
\text { turísticas a las nuevas condiciones del clima. } \\
\text {-Desarrollo de estudios de impactos y vulnerabilidad al cambio } \\
\text { climático sobre los diferentes espacios turísticos. } \\
\text {-Crear sistemas de indicadores que alerten sobre los efectos del } \\
\text { cambio climático en el turismo. } \\
\text {-Evaluación socioeconómica de los efectos del cambio climático en el } \\
\text { turismo y análisis de inversión futura. }\end{array}$ \\
\hline
\end{tabular}

Fuente: Planes Autonómicos de Adaptación al Cambio Climático de las CC.AA. Elaboración propia.

Al tratarse, en todos los casos, de documentos aprobados recientemente, en pocos casos se ha realizado una evaluación de seguimiento y, en todo caso, para el sector turístico, las medidas señaladas han tenido, hasta el momento presente, un grado de implantación bajo.

\section{EL CAMBIO CLIMÁTICO EN LA POLÍTICA TURÍSTICA DE LAS REGIO- NES MEDITERRÁNEAS ESPAÑOLAS}

Las Comunidades Autónomas del litoral mediterráneo español han desarrollado instrumentos programáticos para la aplicación de las políticas públicas en materia de turismo, considerando que el marco competencial en España establece que la ordenación y planificación del turismo corresponde a las comunidades autónomas (art. 148.1.18 a de la Constitución), de tal manera que es en los distintos planes regionales de turismo donde resulta patente la sensibilidad y nivel de preocupación por el cambio climático, aunque ésta sigue siendo muy escasa. 
Así, en Cataluña, donde el turismo es un sector estratégico de su economía y del modelo de organización territorial, la política turística se basa en un instrumento denominado Pla Estratègic de Turisme de Catalunya 2013-2016, (Generalitat de Catalunya, 2013) que define el modelo turístico de Cataluña y los principios directores que orientan la acción de los agentes públicos y privados del sector. El propósito es crear un modelo que permita que Cataluña mantenga la posición de liderazgo entre los primeros destinos turísticos internacionales.

En el diagnóstico previo del turismo que realiza el referido plan, en el apartado de amenazas se indica de forma explícita el cambio climático, que afectará a la diversidad de recursos y reforzará la competitividad del Norte. No obstante, ya en la misma introducción del referido plan, al referirse a lo que se denomina hechos capitales del modelo turístico, se indica que el incremento de temperaturas, debido al cambio climático, supondrá una oportunidad para el sector, por la extensión de la temporada para el turismo de sol y playa. Más adelante, en el desarrollo de los programas que integran el plan, el denominado programa de destinos habla, entre otros aspectos, de la renovación de la oferta obsoleta «teniendo en cuenta las nuevas situaciones climáticas...». También en el programa de excelencia, dentro de la sostenibilidad ambiental, se indica la concienciación del sector sobre la importancia de los efectos del cambio climático y se apunta como proyecto concreto una campaña de sensibilización sobre el tema. No obstante, cuando se observa la tabla de actuaciones priorizadas del plan, con asignación de presupuesto (p. 31), no aparece explícitamente dicha campaña ni acción concreta.

En Baleares, otras de las comunidades que ha hecho del turismo un sector estratégico de su estructura económica y territorial, el instrumento que rige la política turística es el Pla integral de turismo de les Illes Balears 2015-2025 (Govern de les Illes Balears, 2015). En este plan, al referirse a la dimensión ambiental del turismo, se señala (p. 8) que Baleares, uno de los principales destinos del turismo en la Unión Europea, debe llegar a ser un referente medioambiental y ecológico en turismo, con líneas como el uso de las energías renovables y la eficiencia energética. Para ello, prevé introducir una serie de medidas conducentes a reducir las emisiones de gases efecto invernadero, a aumentar la autosuficiencia energética y a mejorar la producción de energía eléctrica, que tienen que llevar implícita una actuación en el sector transporte.

Se entiende que estas acciones favorecerán la generación de nuevas oportunidades de negocio y la dinamización del sector económico. No obstante, a la hora de concretar medidas, el plan de acción 2015, como instrumento operativo, además de mencionar los principios de desarrollo sostenible y calidad medioambiental, no incluye medidas específicas al respecto. Se podría interpretar que los aspectos del cambio climático son competencia de la Oficina del Cambio Climático con la que cuenta esta comunidad, pero sorprende la ausencia de referencias explícitas en su política turística, considerando la importancia estratégica de este sector en el archipiélago.

En el caso de la Comunidad Valenciana, llama poderosamente la atención la inexistencia de referencias al tema cambio climático en su Plan Estratégico Global del Turismo 2010-2020 (Generalitat Valenciana e Invat.tur, 2010). Además, el plan incluye un apartado de prospectiva, con un análisis y percepción del sector turístico, realizado con la participación de los agentes sociales, que se estructura en cuatro apartados clave: entorno; 
infraestructuras y transporte; oferta; y perfil del turista. En el apartado concreto de entorno, se indica de forma explícita: «Percepción de escasa incidencia al cambio climático» (p. 9), lo que lleva a desestimar cualquier línea de acción en esta materia, en el marco de la planificación regional del turismo.

Sorprende el caso de la Región de Murcia porque el instrumento rector de su política turística, el Plan Director de Turismo de la Región de Murcia 2006-2012 (Región de Murcia, 2006), en el marco de la planificación estratégica de esta región, muestra una clara voluntad expansionista del turismo y apuesta por grandes infraestructuras, complejos turísticos de nuevo corte, etc., a pesar de introducir retóricamente el concepto de desarrollo sostenible. Es probable que esta orientación derive del hecho de haber sido formulado en un contexto de crecimiento y grandes expectativas para el incremento de la actividad turística en la región. Pero, en todo el plan no aparece ni una sola mención al tema de la adaptación al cambio climático. Se apunta la existencia de una línea de indicadores para el seguimiento y cumplimiento de los objetivos del plan, dentro de los cuales aparecen indicadores ambientales y su evolución, sin mención alguna a la cuestión del cambio climático.

En Andalucía, el Plan General de Turismo Sostenible de Andalucía 2014-2020 (Junta de Andalucía, 2013) se define como el instrumento básico y esencial en la ordenación de los recursos turísticos para todo el ámbito geográfico de la Comunidad Autónoma y tiene como referencia los once objetivos temáticos aprobados por el Reglamento (UE) $n^{\circ} 1303 / 2013$, por el que se establecen disposiciones comunes sobre los distintos Fondos Europeos, contribuyendo a la consecución de dichos objetivos mediante el desarrollo de una serie de líneas estratégicas y programas que constituyen los ejes fundamentales del Plan. Entre los once objetivos temáticos contemplados, el $5^{\circ}$ lleva por título «Promover la adaptación al cambio climático y la prevención y gestión de riesgos», por tanto, aparece de forma explícita una referencia a este tema como marco principal del plan. Además, para el desarrollo y la programación de este Plan General se han tenido en cuenta una serie de Estrategias andaluzas convergentes con las orientaciones de la Estrategia Europa 2020, entre las que figura la Estrategia Energética 2014-2020 que tiene como finalidad genérica ayudar a desligar crecimiento económico y utilización de recursos, apoyar el cambio hacia una economía con bajas emisiones de carbono, incrementar el uso de fuentes de energía renovables, modernizar nuestro sector del transporte y promover la eficacia energética. Además, este plan tiene también una relación y coherencia con la Estrategia Andaluza ante el Cambio Climático (2002), formada por un conjunto de medidas a ejecutar desde los distintos departamentos del Gobierno andaluz, considerando las medidas con potencial incidencia en las actuaciones de turismo.

Junto al Plan General, la ley de Turismo de esta comunidad autónoma prevé la elaboración de los Marcos Estratégicos para la ordenación de los recursos y las actividades turísticas (MEORAT) que surgen de la conceptualización del territorio como recurso y soporte físico de la actividad turística. Entre otros aspectos, dichos Marcos Estratégicos deben contener la evaluación de la incidencia ambiental del modelo turístico propuesto, incluyendo los efectos del cambio climático y su coherencia con el desarrollo sostenible.

Respecto al Plan General de Turismo Sostenible, lo esencial es que integra diferentes Programas de actuación, como el de coordinación administrativa y de cooperación 
público-privada, en cuyo desarrollo hace una referencia explícita a la necesidad de establecer convenios con otros departamentos de la administración autonómica que incluirán «la protección y reparación de aquellos espacios naturales que puedan verse afectados por el cambio climático, caso de los situados en el ámbito litoral». Asimismo, el programa de apoyo a la calidad y fomento de la sostenibilidad, incluye líneas para prevención y gestión de riesgos en el litoral como consecuencia del cambio climático. Por su parte, el Programa de formación para la profesionalización de los recursos humanos, incorpora entre los conocimientos a adquirir por empresarios y profesionales del sector la concienciación de la necesidad de apoyar el cambio a una economía de baja emisión de carbono, adaptada al cambio climático, que haga un uso eficaz de los recursos y sea medioambientalmente sostenible.

Particularmente interesante resulta el análisis del Informe de Informe de Sostenibilidad Ambiental (Junta de Andalucía, 2014) del plan en cuestión, en cuanto se basa en el cumplimiento de las principales directrices adoptadas por el Consejo Europeo de Gotemburgo de 2001 en la «Estrategia de la Unión Europea a favor del desarrollo sostenible» (COM/2001/264 final y COM/2005/658 final). Esta estrategia pone de manifiesto siete tendencias insostenibles que requieren una intervención, entre las cuales aparece el cambio climático y la energía. Para ello se enumeran toda una serie de objetivos, operativos y cuantificados, y medidas concretas a escala de la UE para alcanzarlos. Y el primer objetivo específico a largo plazo del plan consiste en luchar contra el cambio climático y sus efectos, respetando los compromisos del protocolo de Kioto y en el marco de la estrategia europea sobre el cambio climático.

Entre las medidas que propone el Informe de Sostenibilidad Ambiental, se indica la necesidad de considerar explícitamente el cambio climático en los planes para los que el Plan General de Turismo Sostenible es referencia y marco de actuación. De este modo, los instrumentos y acciones, a tenor del referido Informe, deben considerar en su formulación el cambio climático y adoptar medidas para que ello se traslade a los proyectos que los desarrollen. Y ello teniendo en cuenta las dos direcciones a través de las que incide el cambio climático en la actividad turística. Una viene dada por los efectos que las actividades turísticas pueden ejercer en la emisión de gases de efecto invernadero; por ejemplo a través de la presión asociada al incremento del tráfico rodado en determinadas zonas, del tráfico marino en otras, del consumo energético, etc. La otra vertiente son las consecuencias que el cambio climático puede tener en tres aspectos: la demanda de actividades turísticas, en términos de cantidad y calidad; la variación del atractivo turístico de Andalucía, o de ciertas zonas turísticas andaluzas; y la variación de la competencia, a causa del posible desplazamiento de la demanda hacia nuevas zonas cuyo atractivo puede mejorar por el cambio climático.

\section{MITIGACIÓN Y ADAPTACIÓN AL CAMBIO CLIMÁTICO EN LA EMPRESA TURÍSTICA}

En gran medida las acciones de reducción del cambio climático puestas en marcha en los últimos años, por Estados y empresas, han estado relacionadas con la cuestión energética (reducción de emisiones, energías alternativas). En este campo, y dentro del 
sector turístico se han desarrollado algunas iniciativas dignas de mención. Es el caso de la red europea «Hotel Energy Solutions» ${ }^{16}$, creada en 2008 dentro de la mencionada iniciativa energética europea 2020 y auspiciada por la Organización Mundial del Turismo, que pretende aportar soluciones para la reducción de las emisiones y la huella de carbono en el sector turístico. Entre sus objetivos está la mejora de la eficiencia energética en un $20 \%$ y el uso de energías alternativas en un $10 \%$ del consumo total en hoteles medianos y pequeños del territorio europeo. Por término medio, un hotel en Europa libera anualmente entre $160-200 \mathrm{~kg}$. de $\mathrm{CO}_{2}$ por $\mathrm{m}^{2}$. Mediante la reducción de las emisiones de $\mathrm{CO} 2$, los hoteles pueden hacer una contribución positiva al medio ambiente y, al mismo tiempo, reducir sus costes de operación. Para ello se ha desarrollado una herramienta en red (e-toolkit) que calcula la eficacia energética de un establecimiento hotelero en cualquier tipo de clima y proporciona soluciones para una mayor eficiencia. En este programa participan diversos destinos turísticos de Europa, entre ellos Palma de Mallorca, donde 23 hoteles se han incorporado, en la actualidad, al uso de la herramienta e-toolkit de eficiencia energética.

Un paso más en estas iniciativas de reducción de consumos energéticos y, por ende, de emisiones de gases de efecto invernadero en la empresa turística ha sido la puesta en marcha de la iniciativa «neZEH», que tiene como objetivo acelerar la tasa de renovación de hoteles existentes para transformarlos en edificios de consumo casi nulo (nZEB), en respuesta a la Directiva Europea sobre Eficiencia Energética en Edificios (Directiva 31/2010). Para ello se han seleccionado una serie de proyectos piloto en siete países europeos (Croacia, Grecia, Francia, Italia, Rumanía, Suecia y España), a los que se aplicará una serie de protocolos en la búsqueda de su eficiencia energética. Para el caso español, se han seleccionado 5 proyectos en hoteles de costa, de montaña y rural, de los cuales dos están ubicados en el litoral mediterráneo (Hotel Corona del Mar en Benidorm y Hotel Cala Serena en Palma de Mallorca). Para poder formar parte de este programa los hoteles, y tras una auditoría previa con la herramienta e-toolkit, deben reducir su consumo energético hasta un nivel de excelencia (94 kwh/m2/año) y aumentar la cuota de energías limpias hasta el $50 \%$ del su consumo total.

A las medidas derivadas de la aplicación de programas impulsados desde el sector público, se unen las acciones que están desarrollando desde hace años las empresas turísticas. Tanto touroperadores como cadenas hoteleras han desarrollado desde los años noventa una serie de estrategias y medidas de adaptación al cambio climático que está dando resultados concretos muy interesantes. Así, el mayor grupo de tour operación europeo (TUI) con más de 30 millones de clientes, desarrolla una política sólida de adaptación al cambio climático desde principios de los años noventa del pasado siglo. En efecto, desde principios de 1990, la compañía TUI ha participado en proyectos diseñados específicamente para proteger el clima, con participación de investigadores, administración, empresa privada y sociedad civil. La estrategia climática de TUI se basa en la prevención y reducción de las emisiones y la adaptación de los diferentes sectores de actividad de la empresa con medidas de eficiencia hacia aspectos ambientales y

16 Una explicación detallada de este programa, con inclusión de estudios de caso en el ámbito europeo puede consultarse en http://dtxtq4w60xqpw.cloudfront.net/sites/all/files/docpdf/finalreport.pdf 
específicamente relacionados con el cambio climático. Para ello ha definido una serie de objetivos de sostenibilidad climática y ambiental:

- Apoyar e implementar políticas para reducir y evitar las emisiones de gases de efecto invernadero

- Optimizar los procesos operativos y aplicar tecnologías innovadoras para mejorar la eficiencia

- Comprometerse con objetivos de reducción específicos

- Promover el uso de energías renovables

- Elevar la conciencia de los consumidores y de los empleados para la protección activa del clima

- Cooperar con las organizaciones no gubernamentales, la administración y las instituciones de investigación.

La operadora turística lleva a cabo una evaluación sistemática de su huella ambiental (energía, agua) a partir de la definición de indicadores, ha puesto en marcha un servicio técnico de seguimiento de políticas de protección del clima y ha aprobado un Código de Conducta que incluye el compromiso con la protección del clima como uno de sus principios principales, además de realizar campañas de sensibilización de esta tema entre clientes y socios. Estas cuestiones son de aplicación, como se ha mencionado, a sus diferentes sectores de actividad (transporte aéreo, hoteles, cruceros, vehículos de alquiler). Las acciones puestas en marcha por el touroperador en la última década han sido reconocidas en 2011, por la organización «Carbon Disclosure Project» ${ }^{17}$, que persigue la transparencia de las empresas en materia de gestión ambiental y de puesta en marcha de políticas efectivas de reducción de emisiones de gases, de consumo de agua y de protección de espacios forestales.

En el caso concreto de España, EXCELTUR, la alianza para la excelencia turística, asociación formada por 25 de las más relevantes empresas de la cadena de valor turística que integra los distintos subsectores que forman dicha cadena y que, en definitiva, es el lobby empresarial más importante de este país, ha sido pionera en afrontar nuevo retos para el sector empresarial turístico. Entre sus estudios y publicaciones, se encuentra MONITUR (Exceltur, 2011), ranking de competitividad turística de las comunidades autónomas de España, que analiza la posición competitiva de las 17 comunidades, organizando los indicadores en pilares, uno de los cuales es la ordenación y condicionantes competitivos del espacio turístico. Este pilar integra variables como son la protección del territorio, densidad urbanística de los destinos y compromiso ambiental, y a su vez se desglosa mediante indicadores como el tratamiento de residuos, reutilización de aguas, gestión ambiental de playas y adhesión a programas de compromiso ambiental. No obstante, llama la atención que ningún indicador haga referencia al cambio climático y a sus efectos previsibles.

Por su parte, grandes grupos hoteleros internacionalizados, como Melia, NH o Riu, están desarrollando su propias estrategias de reducción de consumo de energía y agua, en

17 Esta organización fue creada en 2000 y sus informes anuales se han convertido en una referencia importante para empresas e instituciones en materia de políticas y acciones de lucha contra el cambio climático. (Vid. https://www.cdp.net/en-US/Pages/HomePage.aspx). 
el marco de políticas generales de reducción de costes empresariales, que han supuesto la renovación de instalaciones eléctricas y de agua, con efectos palpables de disminución de consumo por plaza hotelera y día en estas dos variables ambientales. De manera que, aunque insertas en concepciones de rentabilidad económica de la empresa, debe valorarse muy positivamente los resultados que se están obteniendo a escala de instalación hotelera, que suponen un ejemplo para cadenas hoteleras de menor dimensión o hoteles de titularidad familiar, de los que hay numerosos ejemplos en España y específicamente en su litoral mediterráneo (vid. tabla 6).

\section{Tabla 6 \\ ESTRATEGIAS DE REDUCCIÓN DE AGUA Y ENERGÍA EN GRANDES CADENAS HOTELERAS}

\begin{tabular}{|l|l|l|}
\hline \multicolumn{1}{|c|}{ CADENA HOTELERA } & \multicolumn{1}{|c|}{ AGUA } & \multicolumn{1}{c|}{ ENERGÍA } \\
\hline RIU Hotels and Resorts & $\begin{array}{l}\text { De 389 1/plaza/día (2013) } \\
\text { a 371 1/plaza/día (2014) }\end{array}$ & $\begin{array}{l}\text { De 16,03 Kw/plaza/noche } \\
\text { (2013) a 15,31 Kw/plaza/ } \\
\text { noche }(2014)\end{array}$ \\
\hline Melia Group & $\begin{array}{l}\text { De 500 1/plaza/día (2013) } \\
\text { a 490 1/plaza/día (2014) }\end{array}$ & $\begin{array}{l}\text { De 22,30 Kw/plaza/noche } \\
(2013) \text { a 21,34 Kw/plaza/ } \\
\text { noche (2014) }\end{array}$ \\
\hline HN Hotels & $\begin{array}{l}\text { De 303 1/plaza/día (2013) } \\
\text { a 300 1/plaza/día (2014) }\end{array}$ & $\begin{array}{l}\text { De 55,52 Kw/habitación/ } \\
\text { noche }(2013) \text { a 51,43 Kw/ } \\
\text { habitación/noche (2014) }\end{array}$ \\
\hline
\end{tabular}

Fuente: Memorias anuales de responsabilidad corporativa de las cadenas hoteleras.

Además de las medidas puestas en marcha por las grandes cadenas hoteleras es necesario destacar, por último, las actuaciones de adaptación que han llevado a cabo empresarios turísticos particulares en los últimos años. Básicamente se trata de actuaciones para el fomento del ahorro de energía y de agua en apartamentos y, sobre todo, en instalaciones hoteleras que se ha difundido al resto de intalaciones de menor tamaño en diversos destinos turísticos. Es el caso de la Costa Brava (Gabarda, Ribas y Daunis, 2015), de la Costa Daurada, de Mallorca, de Benidorm (Rico et al, 2013), del litoral de Murcia y de la Costa del Sol.

En estos casos, surge primero la necesidad de ahorrar agua, a partir de la década de los años ochenta del pasado siglo y a ello se ha unido la necesidad del ahorro de energía, en los últimos quince años debido al incremento de tarifas eléctricas y el aumento de porcentaje en el gasto de energía eléctrica presupuesto de explotación anual de una instalación hotelera. Suele haber, además, un evento importante de sequía ocurrido en los destinos turísticos, que motiva la realización de actuaciones por parte de la iniciativa privada y que complementan o, incluso, suplen las acciones desarrolladas por las administraciones públicas. Así ha ocurrido en Benidorm, tras la sequía de 1978, en el litoral catalán tras las sequías de 1990-95 y de 2008, en Baleares y Costa del Sol, por la sequía de 1990-95 y en el litoral de Murcia por las frecuentes sequías desde los años ochenta del pasado siglo (Martínez Ibarra, 2015). 
Hay que tener en cuenta, asimismo, el papel que han tenido las ayudas a empresas del sector puestas en marcha por las administraciones, estatal y autonómica, en los últimos años en relación con el fomento de medidas generales de sostenibilidad y, específicas, de ahorro de energía y agua. Y asimismo, deben tenerse en cuenta las directrices económicas de las cadenas hoteleras o de particulares de mejora de resultados anuales de explotación en un sector cada vez más competitivo, y que han encontrado en la reducción de gastos de energía y agua un elemento de ahorro importante.

Una relación de medidas puesta en marcha por la planta hotelera de las áreas turísticas del litoral mediterráneo español en los últimos quince años contempla:

- Instalación de grifería y sanitarios con dosificación de caudal en habitaciones.

- Instalación de grifería eficiente en cocinas.

- Sistemas de presión en el suministro de agua de los hoteles.

- Información a los clientes con recomendaciones de ahorro de agua.

- Sistemas eficientes de riego de zonas ajardinadas (goteo, programación de riesgos).

- Mantenimiento de agua en piscinas todo el año, con tratamientos de depuración y cloración.

- Sistemas de ducha de pulsador en piscinas.

- Utilización de agua de pozos propios para rellenado de piscinas (pozos de los años 70 y 80$)$.

- Utilización de electrodomésticos eficientes en cocinas y lavandería (lavaplatos, lavadoras).

- Sistemas combinados de ahorro de agua y energía (agua sanitaria con energía solar).

- Sistemas de «emergencia» para abastecimiento en hoteles (agua de pozos y unidades de desalinización propias en grandes hoteles).

En muchos casos, se han aprovechado procesos de renovación de las plantas hoteleras, y la puesta en marcha de programas de ayudas estatales para llevar a cabo dicha renovación. Y el resultado ha sido una disminución en el consumo de agua y de energía eléctrica (Rico et al., 2013; Gabarda et al., 2015), que ha favorecido la reducción en los gastos anuales de explotación de los hoteles.

Es de notar que tanto organismos públicos (Diputaciones Provinciales) como asociaciones hoteleras en las áreas turísticas han desarrollado planes y estrategias orientadas a la reducción de consumos de agua y energía en el sector turístico, en el marco de políticas de adaptación al cambio climático. Debe tenerse en cuenta que la implantación de medidas de reducción de consumo de agua y la estrecha relación que ello tiene con el gasto energético anual de un establecimiento hotelero, puede llegar a suponer una disminución del $25 \%$ en la factura energética de un hotel; de ahí el interés en el desarrollo de este tipo de medidas por parte de las empresas hoteleras, sea cual sea su tamaño y titularidad.

Para impulsar medidas de ahorro de agua y energía, los hoteles han desarrollado, en los últimos, campañas de sensibilización sobre ahorro y uso sostenible del agua, dirigidas tanto a clientes como a trabajadores. Se trata de campañas que, en algunos casos, comenzaron ya a finales del pasado siglo, pero que se han intensificado en la última década en relación con la mayor atención a las actuaciones de sostenibilidad. Se ha recurrido 
al empleo de carteles o adhesivos informativos en las zonas generales y en las propias habitaciones. En la actualidad, esta es una medida común en buena parte de la planta hotelera del litoral mediterráneo español. Se anima, por ejemplo, a los clientes a utilizar las toallas más de un día y se informa de los beneficios que su acción voluntaria supone para el ahorro de agua y detergente, la disminución de la contaminación, y la reducción de emisiones de $\mathrm{CO}_{2}$ para frenar el cambio climático.

Por último, una línea de actuación futura deberá ser la reutilización de aguas residuales en las propias instalaciones hoteleras. En la encuesta realizada en el presente estudio, se ha puesto de manifiesto la falta total de acciones de los hoteles dentro de esta estrategia de ahorro de agua. En el informe sobre usos del agua en el área metropolitana de Barcelona (Domene, Sauri y Parés, 2005) se señalaba la implantación de redes de aguas grises para inodoros en hoteles como una posible medida de ahorro de agua aplicar en este ámbito de estudio. A pesar de que se señalaban ahorros de agua del $10 \%$ respecto al consumo total anual de un hotel, los autores aconsejaban la necesidad de estudiar bien la viabilidad de la inversión a realizar en función del tamaño de la instalación hotelera. La reutilización del agua utilizada en lavabos y duchas de las habitaciones para los inodoros, a partir de la instalación de depósitos comunitarios para su tratamiento y posterior utilización en redes de aguas grises con destino a los inodoros supone, en efecto, una inversión costosa que debe valorarse a la hora de aplicar esta medida en un hotel. Otra posibilidad, de coste menor, es el aprovechamiento de agua de las duchas existentes en las piscinas de los hoteles para el rellenado diario que debe realizarse en las propias piscinas y que supondría inversiones asumibles en un hotel.

\section{CONCLUSIONES Y AGENDA PARA LOS PRÓXIMOS AÑOS}

Con el inicio del presente siglo, los fundamentos centrales y paradigmas que debían orientar las nuevas estrategias y políticas de turismo aparecían claramente definidos en torno a la sostenibilidad como principio esencial. Los informes de organismos internacionales de turismo, como la propia Organización Mundial del Turismo o el World Travel and Tourism Council, establecieron recomendaciones en ese sentido para países, destinos y empresas. Tal y como indicaba Exceltur, hace ya más de una década, el nuevo paradigma turístico surgía de la confluencia de intereses entre competitividad, calidad, diferenciación y sostenibilidad. En este contexto, los aspectos de sostenibilidad y calidad ambiental centraron la atención en los procesos de consumo de recursos naturales y culturales, emisión de residuos y modelos de implantación del turismo, entre otros aspectos. Todo ello se ha ido traduciendo en la elaboración de guías para la gestión ambiental, herramientas para la conservación del entorno urbano y el paisaje, modelos para la gestión del desarrollo turístico en el territorio, o sistemas para la gestión sostenible de la movilidad. Sin embargo, en el momento actual es evidente que entre los nuevos paradigmas clave para el turismo debería aparecer la adaptación y mitigación de los efectos previsibles del cambio climático, como una preocupación esencial.

A través de un repaso a los instrumentos de política turística del gobierno de España y de las comunidades autónomas del mediterráneo y archipiélagos, se ha tratado de comprobar si existe un nivel preocupación por el previsible efecto del cambio climático, 
partiendo de la idea de que este tema resulta especialmente relevante en el sector turístico, muy vulnerable frente a los impactos previsibles del cambio climático.

La primera impresión es que las referencias al cambio climático en los planes y programas que instrumentan la política turística, tanto del gobierno de España como de las comunidades autónomas analizadas (Cataluña, Andalucía, Comunidad Valenciana, Baleares, Región de Murcia y Canarias), son escasamente visibles e incluso en una buena parte de casos ni siquiera aparecen. Esta escasa presencia es representativa de un nivel ínfimo de preocupación o sensibilidad por los previsibles efectos y necesidades de adaptación, a pesar de que el turismo es un sector estratégico de su economía y, a la vez, una actividad especialmente vulnerable ante los efectos del cambio climático.

Algunos instrumentos de política turística no contienen referencias de ningún tipo al cambio climático, como ocurre en el Plan Nacional e Integral del Turismo de España, o con el Plan Director de Turismo de la Región de Murcia. En otros casos, se menciona el cambio climático únicamente como un factor global, pero del que no se espera especial incidencia, como indica el Plan Estratégico Global del Turismo de la Comunidad Valenciana, resultado de la fase de participación de agentes sociales.

Cuando aparecen referencias al cambio climático en algunos instrumentos de política turística, están en relación con los factores de competitividad global que afectan al turismo, como ocurre en el Pla Estratègic de Turisme de Cataluña, donde incluso el cambio climático se integra en uno de los programas de actuación, pero no en las actuaciones priorizadas.

La excepción relevante, en el sentido de preocupación por el tema, es Andalucía, donde en el Plan General de Turismo Sostenible 2014-2020 consta el interés, tanto en la consideración de efectos previsibles como en el Informe de Sostenibilidad Ambiental y en la incorporación del cambio climático en programas y acciones concretas.

En las próximas décadas las líneas de actuación principales para la adaptación al cambio climático en la escala local en áreas turísticas del litoral mediterráneo español deberán ser las siguientes:

- Energía. Potenciación de programas de mejora de la eficiencia energética.

- Agua: Mantenimiento y potenciación de las actuaciones de ahorro de agua en municipios e instalaciones turísticas privadas.

- Vivienda. Acondicionamiento y/o construcción de viviendas adaptadas a la nueva realidad climática: acondicionamiento térmico, eficiencia en gasto energético y de agua, ubicación en lugares sin peligrosidad natural (inundaciones, temporales en franja costera).

- Ordenación territorial: selección de áreas sin riesgo natural (inundación y costas) para el crecimiento de los núcleos urbanos

- Educación para el riesgo y para el cambio climático. Es la gran asignatura pendiente en España. Aunque se han desarrollado iniciativas de interés, siguen siendo escasas, puntuales y con un eco escaso. Además de la incorporación de contenidos de esta temática en el sistema educativo, será necesario realizar campañas de información y concienciación en los núcleos urbanos y, especialmente, en áreas turísticas con un peso importante de población no autóctona para reducir la elevada vulnerabilidad existente en estos territorios. 
En el proceso de adaptación de la actividad turística al cambio climático en el litoral mediterráneo español, no se encuentran, aún, grandes proyectos ni medidas estructurales, como se ha señalado; pero, comienza a haber iniciativas locales y privadas que tienen su interés y suponen un primer eslabón en una cadena de actuaciones de larga duración. Estamos ante un proceso de medio y largo plazo, que rebasa el período vital de una generación y se corre, en este sentido, el riesgo de que se vaya retrasando la puesta en marcha de medidas a la vista de que los efectos del calentamiento no van a ser visibles a corto plazo. De ahí la necesidad del mantenimiento e incentivación de las políticas públicas en este tema y del apoyo de deben tener las iniciativas que desarrollen el sector privado, como estrategia de supervivencia en los actuales parámetros de desarrollo de la actividad turística en el litoral mediterráneo español, que es una pieza clave del turismo español.

\section{BIBLIOGRAFÍA}

AEMET (Agencia Estatal de Meteorología) (2015): Proyecciones Climáticas para el siglo XXI en España. Disponible en: http://www.aemet.es/es/serviciosclimaticos/cambio_climat [Consultado: Junio 2015].

AMELUNG, B., NICHOLLS, S. y VINER, D. (2007): «Implications of global climate change for tourist flows and seasonality», Journal of Travel Research, 45, pp. 285-296.

ANTON CLAVÉ, S., RULLAN SALAMANCA, O. y VERA REBOLLO, J.F. (2011): «Mass Tourism Development on the Mediterranean Coast», Tourism Geographies, 13 (3), pp. 495-501.

BAÑOS CASTIÑEIRA, C.J., VERA REBOLLO, J.F. y DÍEZ SANTO, D. (2010): «El abastecimiento de agua en los espacios y destinos turísticos de Alicante y Murcia», Investigaciones Geográficas, $\mathrm{n}^{\circ}$ 51, pp. 81-105.

BARTON, J.R. (2009): «Adaptación al cambio climático en la planificación de ciudadesregiones», Revista de Geografía Norte Grande, 43, pp. 5-30.

BESANCENOT, J. P. (1991) Clima y Turismo. Ed. Masson, Barcelona, 224 p.

BIESBROEK, R.G., SWART, R. J., CARTER, T. R., COWAN, C., HENRICHS, TH., MELA, H., MORECROFT, M.D. and REY, D. (2010): «Europe adapts to climate change: Comparing National Adaptation Strategies», Global Environmental Change, 20, pp. 440-450.

CERON, J.P. and DUBOIS, G (2005): «Limits to tourism ? A backcasting scenario for a sustainable tourism mobility in 2050». Symposium «The end of Tourism? Mobility and Local-global connections», Eastbourne, CTPS.

CUNILlERA, J., MÁS, J., MANZANO, A., PRAT N., MUNNE, A. y SAURÍ, D. (Eds.) (2009): Aigua i Canvi Climàtic. Barcelona: Agència Catalana de l'Aigua.

DUBOIS, G. and CERON, J.P. (2006): «Tourism and climate change: Proposals for a research agenda», Journal of Sustainable Tourism, 14 (4), pp. 399-415.

DOMENE, E., SAURÍ, D. y PARÉS, M. (2005): «Urbanization and sustainable resource use: the case of garden watering in the Metropolitan Region of Barcelona», Urban Geography, Vol. 26, 6, pp. 520-533. 
ESPON Climate. (2011): Climate Change and Territorial Effects on Regions and Local Economies. Main Report. Available at: http://www.espon.eu/export/sites/default/Documents/Projects/AppliedResearch/CLIMATE/ESPON_Climate_Final_Report-Part_BMainReport.pdf.[Consultado: Julio 2015].

EXCELTUR (2011): MoniTUR 2010. Monitor de competitividad turística relativa de las comunidades autónomas españolas. Exceltur y Deloitte, 75 pp. Disponible en: http:// exceltur.org/wp-content/uploads/2014/10/MONITUR-2010_INFORME.pdf. [Consultado: Noviembre 2015].

FEDERACIÓN ESPAÑOLA DE MUNICIPIOS Y PROVINCIAS (2006): Cambio climático en las ciudades costeras. Red Española de Ciudades por el Clima. Ministerio de Medio Ambiente, Madrid, 172 pp.

FEDERACIÓN ESPAÑOLA DE MUNICIPIOS Y PROVINCIAS (2007): Guía práctica para la aplicación de la Estrategia Local de Cambio Climático. Red Española de Ciudades por el Clima. Ministerio de Medio Ambiente, Madrid, 670 pp.

FEDERACIÓN ESPAÑOLA DE MUNICIPIOS Y PROVINCIAS (2009): Metodología para el cálculo del Sistema de Indicadores de Diagnóstico y Seguimiento del Cambio Climático. Red Española de Ciudades por el Clima. Ministerio de Medio Ambiente, Bilbao, $61 \mathrm{pp}$.

GABARDA MALLORQUÍ, A., RIBAS PALOM, A. y DAUNIS I ESTADELLA, J. (2015): «Desarrollo turístico y gestión eficiente del agua. Una oportunidad para el turismo sostenible en la Costa Brava (Girona)», Investigaciones Turísticas nº 9, Universidad de Alicante, pp. 50-69.

GENERALITAT DE CATALUNYA (2013): Pla estratègic de turisme de Catalunya 2013 - 2016 i Directrius nacionals de turismo. Catalunya Visió 2020, 35 pp. Disponible en: http://empresaiocupacio.gencat.cat/ca/treb_departament/emo_plans_actuacio/. [Consultado: Julio 2015].

GENERALITAT VALENCIANA E INVA.TUR (2010): Plan Estratégico Global del Turismo de la Comunitat Valenciana 2010-2020. Visión y ejes estratégicos: documento de síntesis. València. Disponible en: http://www.turisme.gva.es/opencms/opencms/ turisme/es/files/pdf/otros/Plan_Estratxgico_Global_del_Turismo_de_la_Comunitat_ Valenciana_2010-2020.pdf. [Consultado: Julio 2015].

GÓMEZ MARTÍN, M.B., ARMESTO LÓPEZ, X. y MARTÍNEZ IBARRA, E. (2014): «The Spanish tourist sector facing extreme climate events: a case study of domestic tourism in theheat wave of 2003». International Journal of Biometeorology, 58, pp. 781-797.

GÓMEZ MARTÍN, M.B., ARMESTO LÓPEZ, X., CORS, M. y MUÑOZ, J. (2014): "Adaptation strategies to climate change in the tourist sector: the case of coastal tourism in Spain». Tourism. An International Interdisciplinary Journal, Vol. 62, (3), pp. 293-308.

GOSSLING, S. and PEETERS, P. et al. (2012): «Tourism and water use: Supply, demand and security. An international review.» Tourism Management, 33, pp. 1-15.

GÖSSLING, S., PEETERS, P. and SCOTT, D. (2008): «Consequences of Climate Policy for International Tourist Arrivals in Developing Countries». Third World Quarterly, 29 (5), pp. 873-901. 
GOVERN DE LES ILLES BALEARS (2015): Plan Integral de Turismo de las Islas Baleares 2015-2025. Consellería de Turisme i Esports. Palma, 84 pp. Disponible en: http:// balearicislandstourism.info/PITIB/index.php. [Consultado: Julio 2015].

HALL, C.M. and J. HIGHAM (Eds.) (2005): Tourism, recreation and climate change: International perspectives. Clevedon UK: Channel View Publications.

HUNT, A. and WATKISS, P. (2011): Climate change impacts and adaptation in cities: a review of the literature. Climatic Change, 104 (1), pp. 13-49.

INSTITUTO DE TURISMO DE ESPAÑA (2012): Plan Nacional e Integral de Turismo 2012-2015. Ministerio de Industria, Energía y Turismo, Secretaría de Estado de Turismo, Turespaña, Madrid, 124 pp. Disponible en: http://www.tourspain.es/es-es/ VDE/Documentos\%20Vision\%20Destino\%20Espaa/Plan\%20Nacional\%20e\%20Integral\%20de\%20Turismo\%202012_2015_FINAL_REVISADO\%20150313.pdf. [Consultado: Noviembre 2015].

IRIGOY, I., ARTIGUES, A.A., y BLAZQUEZ-SALOM, M. (2013): «El papel de Estado en la renovación urbano-turística de espacios turísticos. El caso de la playa de Palma, Mallorca, España», Rev. Bitacora22, 1, Universidad Nacional de Colombia, pp. 141-152.

JARVA, J., NUOTTIMÄKI, K., KANKAANPÄÄ, S. and TARVAINEN, P. (2014): Climate-Proof Living Environment. Methodologies, tools and practical recommendations for climate change adaptation in the Kymenlaakso and Uusimaa regions and the Helsinki Metropolitan Area. Geological Survey of Finland, Helsinki, 55 pp.

JCR (2014): Climate Impacts in Europe. The JRC PESETA II. European Commission, Luxembourg, $155 \mathrm{pp}$.

JUNTA DE ANDALUCÍA (2014): Plan General de Turismo Sostenible de Andalucía 2014-2020. Informe de Sostenibilidad Ambiental. Consejería de Turismo y Comercio, Secretaría General para el Turismo, 159 pp. Disponible en:

http://www.turismonuevasideas.org/sites/default/files/docplanes/20141126_informe_ sostenibilidad_ambiental_pgtsa.pdf

JUNTA DE ANDALUCÍA (2013): Plan General de Turismo Sostenible de Andalucía [2014 - 2020], Consejería de Turismo y Comercio, Junta de Andalucía, 2 vols. Disponible en: http://www.turismonuevasideas .org/plang/documentos-general. [Consultado: Noviembre 2015].

KAZMIERCZAK, A. y CARTER, J. (2010): Adaptation to climate change using green and blue infrastructure. A data base of case studies. Database prepared for the Interreg IVC Green and blue space adaptation for urban areas and eco towns (GRaBS) project. University of Manchester., 182 p. (Disponible en: http://www.grabs-eu.org/membersArea/files/Database_Final_no_hyperlinks.pdf). [Consultado: Junio 2015].

LOSADA, I., IZAGUIRRE, C. y DIAZ, P. (2014): Cambio climático en la costa española . Oficina Española de Cambio Climático, Ministerio de Agricultura, Alimentación y Medio Ambiente. Madrid, 133 p.

MARCH, H., SAURÍ, D. and OLCINA, J. (2014): «Rising Temperatures and Dwindling Water Supplies? Perception of Climate Change Among Residents of the Spanish Mediterranean Tourist Coastal Areas», Environmental Management, n 53, pp. 181-193. 
MARCOS M., G. JORDÀ, D. GOMIS y B. PÉREZ, (2011): «Changes in storm surges in southern Europe from a regional model under climate change scenarios», Global and Planetary Change, 77, pp. 116-128.

MARCOS M., M.N. TSIMPLIS y A.G.P. SHAW, (2009): «Sea level extremes in southern Europe», Journal of Geophysical Research, 114, C01007.

MARTÍNEZ IBARRA, E. (2015): «Climate, water and tourism: causes and effects of droughts associated with urban development and tourism in Benidorm (Spain)», International Journal of Biometeorology, 59 (5), pp. 487-501.

MELIÁ HOTELS GROUP (2014): Informe Anual y RSC. Madrid, 68 pp.

MIRO PÉREZ, J. (2014): Downscaling estadístico de series climáticas mediante redes neuronales. Reconstrucción en alta resolución de la temperatura diaria para la Comunidad Valenciana. Interpolación espacial y análisis de tendencias (1948-2011). Tesis doctoral. Inédita. Universidad de Alicante, $523 \mathrm{pp}$.

NH HOTEL GROUP (2014): Informe Anual 2014. Memoria de Responsabilidad Corporativa. Madrid, $67 \mathrm{pp}$.

OLCINA CANTOS, J. (2012): «Turismo y cambio climático: una actividad vulnerable que debe adaptarse», Investigaciones Turísticas, 4, pp. 1-34.

OLCINA CANTOS, J. (2014a) «El turismo ante el cambio climático», en Turismo y Territorio. Innovación, renovación y desafíos (López Palomeque, F. y Cànoves Valiente, G., eds.). Tirant Lo Blanch, Valencia. pp. 615-659. ISBN: 978-84-16062-16-4.

OLCINA CANTOS, J. (2014b): «Cambios en la consideración territorial, conceptual y de método de los riesgos naturales», en Enfrentados a un destino adverso. De las calamidades naturales hacia las ciencias cindinicas (Calvo García-Tornel, F., Ed.) Ed. Geo-Crítica. Universidad de Barcelona, pp. 47-68. ISBN: 978-84-941933-6-1.

ORGANIZACIÓN MUNDIAL DEL TURISMO (2015): Panorama OMT del Turismo Internacional, edición 2015. Madrid, OMT, 16 pp.

REGIÓN DE MURCIA (2006): Plan Director de Turismo de la Región de Murcia 2006/2012. Consejería de Turismo, Comercio y Consumo. Disponible en: http:// www.carm.es/web/pagina?IDCONTENIDO=11332\&IDTIPO=100\&RASTRO=c109 5\$m11291. [Consultado: Noviembre 2015].

RICO AMORÓS, A., SAURÍ PUJOL, D., OLCINA CANTOS, J. y VERA REBOLLO J.F. (2013): «Beyond Megaprojects?. Water Alternatives for Mass Tourism in Coastal Mediterranean Spain», Water Resources Management, 01/2013; 27 (2). DOI: 10.1007/ s11269-012-0201-3.

RICO-AMOROS, A., OLCINA-CANTOS, J. and SAURÍ, D. (2009): «Tourist Land Use Patterns and Water Demand. Evidence from the Western Mediterranean», Land Use Policy, 26, pp. 493-501.

RIU HOTELS and RESORTS (2014): Achievements 2014. Corporate Social Responsibility. $30 \mathrm{pp}$.

ROSELLÓ, J. (2011): «España, Turismo y cambio climático», Economistas, n 127 , Madrid, pp. 28-34.

SAURÍ, D., OLCINA, J., MARCH, H., MARTÍN-VIDE, J., VERA, F., PADILLA, E. and SERRA-LLOBET, A. (2013): «Tourism, Climate Change and Water Resources: Coastal Mediterranean Spain as an Example», in European Climate Vulnerabilities 
and Adaptation: A Spatial Planning Perspective, Publisher: John Wiley \& Sons, Ltd, Editors: Philipp Schmidt-Thomé, Stefan Greiving, pp. 231-252.

SCHMIDT-THOMÉ. P. and KLEIN, J. (Ed.) (2013): Climate Change Adaptation in practice. Wiley-Blackwell, Oxford, 327 pp.

SCOTT, D. (2006): «Climate change and sustainable tourism in the 21st century», in Cukier, J. (Ed.) Tourism Research: Policy, Planning, and Prospects . Waterloo. Department of Geography, University of Waterloo, pp. 175-248.

SKILIRIS, N., SOFIANOS, S., GKANASOS, A., MANTZIAFOU, A., VERVATIS, V., AXAOPOULOS, P. y LASCARATOS, A. (2012): «Decadal scale variability of sea surface temperature in the Mediterranean sea in relation to atmospheric variability». Ocean Dynamics, 62, pp. 13-30.

VERA REBOLLO, J.F. y BAÑOS, C.J. (2010): «Renovación y reestructuración de los destinos turísticos consolidados del litoral: las prácticas recreativas en la evolución del espacio turístico», Boletín de la Asociación de Geógrafos Españoles, n ${ }^{\circ}$ 53, pp. 329-353.

VERA, J.F., RODRÍGUEZ. I, y CAPDEPÓN, M. (2010): «Reestructuración y competitividad en destinos maduros de sol y playa: la renovación de la planta hotelera de Benidorm». En XIII Congreso Internacional de Turismo Universidad y Empresa: renovación de destinos turísticos consolidados.

WORLD ECONOMIC FORUM (2015): Travel and Tourism Competitiveness Report 2015. Disponible en: http://reports.weforum.org/travel-and-tourism-competitivenessreport-2015/economy-rankings/

WORLD TRAVEL AND TOURISM COUNCIL (2009) Leading the Challenge on Climate Change. London. World Travel \& Tourism Council. 
